\title{
Multimodality tumor imaging targeting integrin $\alpha_{v} \beta_{3}$
}

Weibo Cai, Sanjiv Sam Gambhir, and Xiaoyuan Chen

Stanford University School of Medicine, Stanford, CA, USA

BioTechniques 39:S14-S25 (December 2005)

doi 10.2144/000112091

The cell adhesion molecule integrin $\alpha_{v} \beta_{3}$ is an important player in the process of tumor angiogenesis and metastasis. Antibodies, peptides, peptidomimetics, and small molecule antagonists against integrin $\alpha_{v} \beta_{3}$ have been shown to induce endothelial apoptosis, to inhibit tumor angiogenesis, and to increase endothelial permeability. The ability to quantitatively image integrin $\alpha_{v} \beta_{3}$ expression in vivo in a noninvasive manner may shed new light into the mechanism of angiogenesis and antiangiogenic treatment efficacy based on integrin antagonism. Tumor integrin expression imaging will also aid in lesion detection, patient stratification, new anti-integrin drug development/validation, as well as treatment monitoring and optimization. This review summarizes the recent advances in multimodality imaging of tumor integrin $\alpha_{v} \beta_{3}$ expression using magnetic resonance imaging (MRI), ultrasound, near-infrared (NIR) fluorescence, single photon emission computed tomography (SPECT), and positron emission tomography (PET).

\section{INTRODUCTION}

\section{Molecular Imaging}

Molecular imaging refers to the characterization and measurement of biological processes at the molecular level $(1,2)$. Conventional imaging modalities that detect anatomical and functional changes of tumor vascularity during angiogenesis, tumor growth, and upon antiangiogenic treatment provide little or no information regarding the specific molecular markers on newly formed blood vessels, tumor cells, and the molecular changes upon therapy. Molecular imaging takes advantage of traditional diagnostic imaging techniques and introduces molecular probes to determine the expression of indicative molecular markers of the tumor development at different stages (2-4). Detection of these molecular markers permits much earlier diagnosis, earlier treatment, and better prognosis. Subsequent profiling to identify suitable treatment targets could lead to individualized therapy and treatment monitoring. Molecular imaging technologies include, but are not limited to, positron emission tomography (PET), single photon emission computed tomography (SPECT), magnetic resonance imaging (MRI), magnetic resonance spectroscopy (MRS), optical bioluminescence, optical fluorescence, and ultrasound $(2,5)$. In computed tomography (CT), the images are obtained because tissues absorb X-rays differently as they pass through the body, therefore providing mainly anatomical information. Since CT signal is rarely specific at the molecular level, it will not be discussed here.

Since many tumors are quite heterogeneous, tissue sampling does not always represent the biochemical or pathological processes of the disease. Furthermore, temporal studies usually need large numbers of animals to be sacrificed at various time points to obtain statistically significant results. Noninvasive imaging of genetic and cellular processes at the molecular level will compliment the established ex vivo molecular biological assays and provide both spatial and temporal dimensions to our understanding of various diseases. Two prerequisites need to be satisfied in order to image and quantify biological processes in vivo noninvasively: (i) a probe composed of a label that can be detected with high sensitivity and a ligand that binds specifically and with high affinity to the target and (ii) a sensitive, high-resolution imaging instrument to detect the signal noninvasively. In this review, we will highlight the recent advances in developing molecular imaging probes and techniques targeting a tumor-specific molecular marker, integrin $\alpha_{v} \beta_{3}$.

\section{Tumor Angiogenesis and Metastasis}

Angiogenesis, the formation of new blood vessels from preexisting blood vessels, is a fundamental process occurring during tumor progression (6). Angiogenesis depends on the balance between pro-angiogenic molecules [vascular endothelial growth factor (VEGF), fibroblast growth factor (FGF), epidermal growth factor (EGF), etc.] and antiangiogenic molecules (angiostatin, endostatin, etc.) $(7,8)$. The fact that tumors are dependent on blood supply has inspired many scientists to search for antiangiogenic molecules and to design antiangiogenic strategies for cancer treatment and prevention of cancer recurrence and metastasis (9-11). Tumor angiogenesis differs significantly from physiological angiogenesis. The differences include aberrant vascular structure, altered endothelial cell-pericyte interactions, abnormal blood flow, increased permeability, and delayed maturation $(6,12)$. Most tumors start growing as avascular dormant nodules until they reach a steady-state level of proliferating and apoptosing cells. Angiogenesis begins with perivascular detachment and vessel dilation, followed by angiogenic sprouting, new vessel formation and maturation, and the recruitment of perivascular cells. Blood-vessel formation continues as the tumor grows, feeding on hypoxic and necrotic areas of the tumor for essential nutrients and oxygen.

Cancer cells spread throughout the body by metastasis (13-16). Metastasis occurs through several steps. First, cancer cells lose E-cadherin-dependent intercellular adhesions, acquire a migratory phenotype, detach from neighboring cells, penetrate the basement membrane, and invade the interstitial matrix. Second, tumor cells penetrate into blood vessels and lymphatic vessels and enter the circulatory system, a process called intravasation. After reaching the bloodstream, tumor cells often adhere to platelets and leukocytes, forming emboli that stop in the microcirculation of target organs more easily than individual tumor cells. Finally, metastatic cells exit the bloodstream (extravasation) and undergo expansive growth within the parenchyma of the target organ.

\section{Role of Integrin $\alpha_{v} \beta_{3}$ During Tumor Progression}

Molecules regulating angiogenesis include growth factor receptors, tyrosine kinase receptors, $\mathrm{G}$ protein-coupled receptors for angiogenesis modulating proteins, and integrins (6-8). Integrins are a family of adhesion molecules consisting of two noncovalently bound transmembrane subunits $(\alpha$ and $\beta)$, both type I membrane proteins with large extracellular segments that pair to create heterodimers with distinct adhesive capabilities $(17,18)$. In mammals, $18 \alpha$ and $8 \beta$ subunits assemble into 24 different receptors. Increasing amounts of evidence now imply that integrin signaling plays a key role in tumor angiogenesis and metastasis (19-21). Integrins expressed on endothelial cells modulate cell migration and survival during angiogenesis, while integrins expressed on carcinoma cells potentiate metastasis by facilitating invasion and movement across blood vessels. Efficient tumor invasion requires partial degradation of the extracellular matrix (ECM) at the invasion front. The matrix metalloproteinases (MMPs) 
are the major proteases involved in remodeling the ECM (15). The $\alpha_{v} \beta_{3}$ integrin, which binds to arginine-glycine-aspartic acid (RGD)containing components of the interstitial matrix, such as vitronectin, fibronectin, and thrombospondin, is significantly up-regulated on endothelium during angiogenesis but not on quiescent endothelium (21-23). The special role of integrin $\alpha_{v} \beta_{3}$ in tumor invasion and metastasis arises from its ability to recruit and activate MMP-2 and plasmin, which degrade components of the basement membrane and interstitial matrix (24). Research has shown that tumor expression of integrin $\alpha_{v} \beta_{3}$ correlates well with tumor progression in several malignancies such as melanoma (25), glioma (26), ovarian cancer $(27)$, and breast cancer $(28,29)$. Inhibition of $\alpha_{v}$-integrin activity by monoclonal antibodies (MAbs), cyclic RGD peptide antagonists, and peptidomimetics has also been shown to induce endothelial cell apoptosis (30), to inhibit angiogenesis (20), and to increase endothelial monolayer permeability (31).

\section{Integrin $\alpha_{v} \beta_{3}$ as the Imaging Target}

For a targeting approach aimed at monitoring tumor angiogenesis and metastasis, the sufficient level of accessible tumor specific targets is essential for the detection and delineation of lesions from background by imaging technologies. Integrin $\alpha_{v} \beta_{3}$, the most extensively studied in the integrin family, serves as an excellent molecular marker for tumor angiogenesis and metastasis imaging, since it is not readily detectable in quiescent vessels but becomes highly expressed in angiogenic vessels (19). The ability to noninvasively visualize and quantify integrin $\alpha_{v} \beta_{3}$ expression level will provide new opportunities to document tumor (tumor cells and sprouting tumor vasculature) integrin expression, to more appropriately select patients for anti-integrin treatment, and to monitor treatment efficacy in integrin-positive patients. Several review articles on tumor angiogenesis imaging have partially covered some integrin targeting approaches $(32,33)$. In this review article, recent advances in both nonradionuclide (MRI, ultrasound, and optical) and radionuclide imaging (SPECT and PET) of tumor integrin $\alpha_{v} \beta_{3}$ will be summarized.

\section{NONRADIONUCLIDE IMAGING OF INTEGRIN $\alpha_{v} \beta_{3}$ EXPRESSION}

\section{Magnetic Resonance Imaging}

The major advantage of MRI over radionuclide or optical imaging is its higher spatial resolution (usually submillimeter level). However, $\mathrm{MRI}$ is many orders of magnitude less sensitive than radionuclide and optical techniques, which means that much larger amounts of molecular probes must be retained at the target for detectable MRI signal (34). High mass amounts of probe can be toxic, and this must be carefully studied before any MRI probe is translated into the clinic. The inherent low sensitivity of MRI can be only partially compensated by working at relatively high magnetic fields (4.7-14 $\mathrm{T})$, using hardware and software dedicated to small animal imaging and much longer acquisition times during imaging.

In an animal model, Sipkins et al. first demonstrated the use of antibody-coated paramagnetic liposomes (300-350 nm in diameter) containing $\mathrm{Gd}^{3+}$ for MRI imaging of integrin $\alpha_{v} \beta_{3}$ expression (35). Imaging of a rabbit model of squamous cell carcinomas (V2) was achieved by directly targeting paramagnetic agents to the angiogenic vasculature using LM609, a mouse anti-human integrin $\alpha_{v} \beta_{3}$ MAb (Figure 1). Anderson et. al. (36) also reported site-directed contrast enhancement of angiogenic vessels in vivo using antibodycoated MRI contrast agent. The targeted contrast agent consists of Gd-perfluorocarbon nanoparticles conjugated to integrin $\alpha_{v} \beta_{3}$ antibody DM101 (400-700 nm in diameter). The study was carried out in a rabbit corneal micropocket model, where neovasculature was induced in the cornea using basic FGF. However, only a modest increase $(<25 \%)$ in the average MR signal intensity was observed after $90 \mathrm{~min}$.

Winter et al. attached peptidomimetic integrin $\alpha_{v} \beta_{3}$ antagonist to magnetic nanoparticles for MRI imaging under common clinical field strength of $1.5 \mathrm{~T}(37,38)$. Two animal models were used, New Zealand white rabbits implanted with $\mathrm{Vx}-2$ tumors and an atherosclerosis model. In the $\vee x-2$ model, integrin $\alpha_{v} \beta_{3}$-targeted paramagnetic nanoparticles increased MRI signal dramatically in the periphery of the tumor at $2 \mathrm{~h}$ postinjection (p.i.). Similar increases in MR contrast were also observed within the walls of some vessels proximate to the tumor. Despite the relatively large size (about 270 $\mathrm{nm}$ in diameter), these nanoparticles penetrated into the leaky tumor neovasculature but did not migrate into the interstitium in an appreciable amount, since only marginal increase in MR signal was observed at $2 \mathrm{~h}$ (characteristic of passive targeting rather than integrin-specific targeting). Immunohistochemistry of integrin $\alpha_{v} \beta_{3}$ confirmed the extent and distribution of neovascularity observed by MRI. In the atherosclerosis model, enhancement in the MRI signal was also observed among rabbits that received integrin-targeted nanoparticles. Histology and immunohistochemistry confirmed the proliferation of angiogenic vessels within the aortic adventitia of the atherosclerotic rabbits as compared with control animals. Since this integrin-targeting nanoparticle system can carry a variety of drugs in its lipid membrane, it may have potential for simultaneous molecular imaging and site-directed drug delivery for early atherosclerotic disease.

Very recently, athymic nude mice bearing human melanoma tumors were also imaged using systemically injected $\alpha_{v} \beta_{3}$ integrintargeted paramagnetic nanoparticles (25). Contrast enhancement of neovascularity in animals that received targeted nanoparticles increased significantly by $2 \mathrm{~h}$ as compared with nontargeted paramagnetic nanoparticles. MRI results were also supported by histology. This technique may be employed to noninvasively detect small regions of angiogenesis associated with nascent melanoma tumors, as well as to phenotype and to stage other integrin-positive tumors in a clinical setting.

In all these studies, the targeted paramagnetic nanoparticles are coated with either antibodies or small peptidic/peptidomimetic integrin $\alpha_{v} \beta_{3}$ antagonists. Coating the paramagnetic nanoparticles with peptides or peptidomimetics is potentially better than antibodies, since hundreds even thousands of peptides/peptidomimetics can be attached to the nanoparticles, which leads to much higher local concentration of the ligand and higher binding affinity. Moreover, not only do antibodies add to the already large size of the nanoparticle contrast agents, antibody-coated contrast agents also stay in the circulation system much longer while peptide- or peptidomimetics-coated contrast agents home to the target faster and that gives better contrast.

\section{Ultrasound}

Because of its low cost, high availability, and safety, ultrasonography is the most commonly used clinical imaging modality. Highfrequency $(>20 \mathrm{kHz})$ sound waves are emitted from a transducer placed against the skin, and ultrasound images are obtained based on the sound wave reflected back from the internal organs (39). The ultrasound contrast is dependent on the sound speed, sound attenuation, backscatter, and the imaging algorithm. Ultrasound imaging using diagnostic ultrasound instrumentation operated in the $7.5-15 \mathrm{MHz}$ frequency range has been applied to several small animal models.

Ellegala et al. reported the ultrasound imaging of tumor angiogenesis using integrin $\alpha_{v} \beta_{3}$-targeted microbubbles (40). Athymic nude rats were inoculated intracerebrally with U87MG human glioma cells. On 2 or 4 weeks after implantation, contrast-enhanced ultrasound (CEU) was performed using microbubbles (3-4 $\mu \mathrm{m}$ 
in diameter) targeted to integrin $\alpha_{v} \beta_{3}$ by surface conjugation of echistatin, a disintegrin containing an RGD sequence that can be recognized by many membrane-associated adhesion receptors including integrin $\alpha_{v} \beta_{3}$. CEU perfusion imaging using nontargeted microbubbles was also performed to determine tumor microvascular blood volume and blood velocity. It was found that CEU signal from targeted microbubbles in tumors increased significantly from 2 to 4 weeks. The signal was highest at the periphery of tumors, where $\alpha_{v}$-integrin expression was most prominent based on immunohistochemistry, which correlated well with tumor microvascular blood volume. In another study, the integrin $\alpha_{v}$-targeting microbubbles were prepared by conjugating echistatin (MBE) or the MAb against murine $\alpha_{v}(\mathrm{MBA})$ to the surface (41). Control microbubbles (MBC) were also prepared. The microvascular behavior of these microbubbles was assessed by intravital microscopy of the cremaster muscle in mice treated for 4 days with the sustained release of FGF2. It was observed that microvascular retention was much greater for MBE and MBA than MBC, where the microbubble retention was minimal. The signal from targeted microbubbles (MBE and MBA) also correlated quite well with the blood volume determined by CEU perfusion imaging. In yet another study, hindlimb ischemia was produced in rats by ligation of an iliac artery (42). Immediately after ligation and at subsequent intervals from 4 to 28 days, targeted CEU imaging of integrin expression was performed using microbubbles conjugated with echistatin. It was observed that iliac artery ligation led to a $65 \%-70 \%$ reduction in blood flow and oxygen tension. In untreated ischemic muscle, blood flow and oxygen tension partially recovered by weeks 2 to 4 , and signal from integrin-targeted microbubbles reached maximum between 4 to 7 days, which was before the blood flow increase. FGF-2-treated muscle had a greater rate and extent of blood flow recovery and greater signal intensity from integrin-targeted microbubbles as compared to control animals.
Since acoustic destruction of "payload-bearing" microbubbles may be used to deliver drugs or to augment gene transfection (43), angiogenesis-targeted microbubbles may also have applications in site-specific therapy for ischemic tissues or tumors. Of course, further characterization of integrin $\alpha_{v}$-targeted microbubbles in physiological models of ischemia or tumor angiogenesis is needed to validate these potential applications. So far, it is still unclear whether this approach will lead to additional diagnostic and prognostic information compared to those already used in the clinic.

\section{Optical Imaging}

One advantage of optical imaging is that multiple probes with different spectral character could potentially be used for multichannel imaging. The major drawback of optical imaging of living subjects is the poor tissue penetration of light. Due to the limited penetration and intense scattering of light, optical imaging will be only possible in humans in limited sites such as the tissues and lesions close to the surface of the skin, tissues accessible by endoscopy, and intraoperative visualization. Even though optical imaging may not be widely used in clinical settings, near-infrared (NIR; 700-900 $\mathrm{nm}$ ) approaches provide opportunities for rapid and cost-effective preclinical evaluation in small animal models before the more costly radionuclide-based imaging studies, since the absorbance spectra for all biomolecules reach minima in the NIR region, which provides a clear window for in vivo optical imaging (44). Charged-coupled device (CCD) cameras have been developed to more efficiently detect the light emitted from the body (45), and fluorescencemediated tomography has also been developed recently (46). The subject is exposed to continuous wave or pulsed light from different sources, and multiple detectors arranged in a spatially defined order in an imaging chamber are used to capture the emitted light. Mathematical processing of this information gives the reconstructed
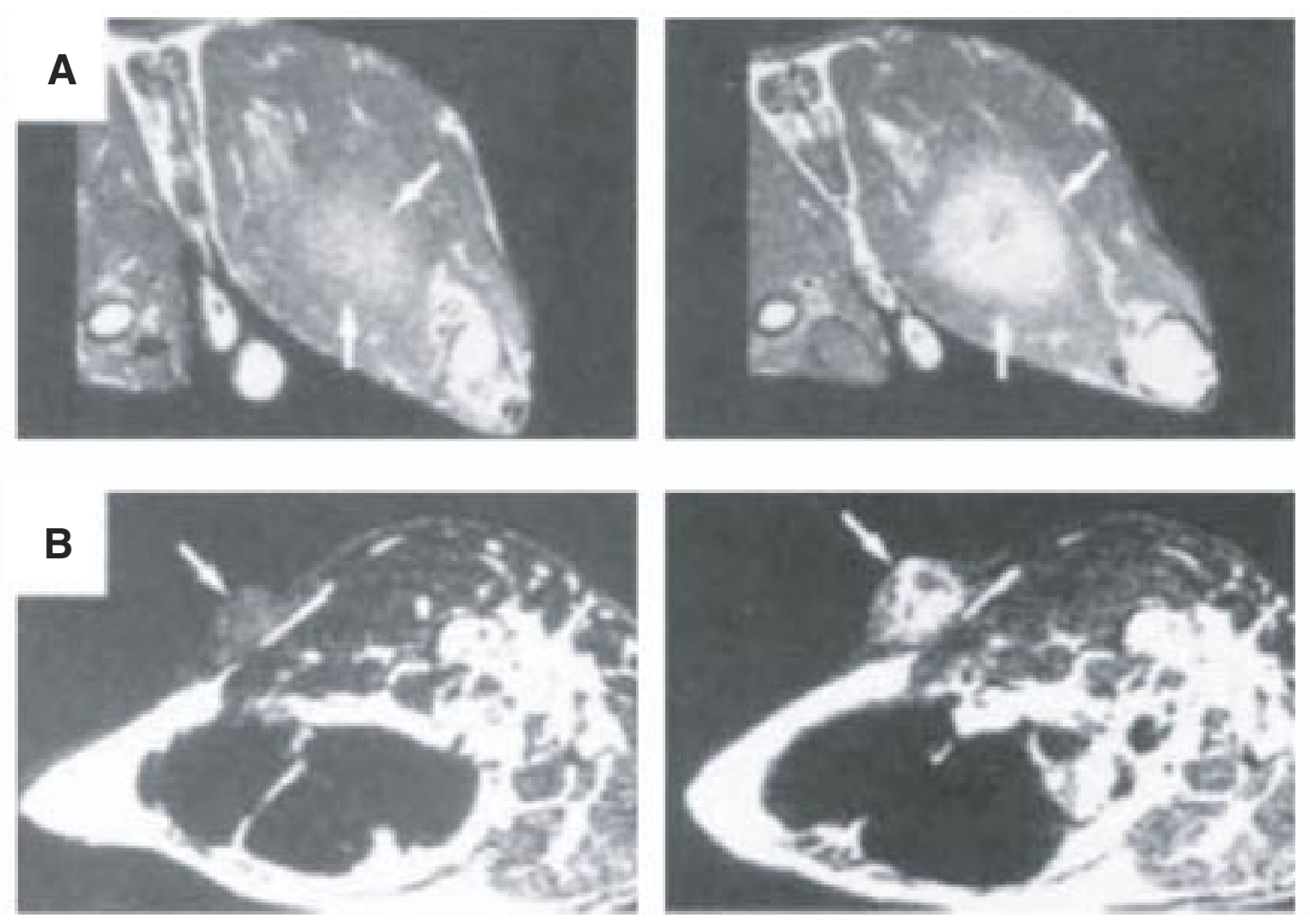

Figure 1. Magnetic resonance imaging (MRI) of tumor angiogenesis in vivo. (A) Axial images of an intramuscular tumor before (left) and after (right) administration of integrin $\alpha_{v} \beta_{3}$-targeted liposomes. (B) Visualization of a subcutaneous tumor precontrast (left) and postcontrast (right). Adapted from Reference 35 . 
tomographic image. Improvement in the algorithm and extensive mathematical validation is needed for practical implementation.

We first demonstrated that NIR fluorescent dye Cy ${ }^{\mathrm{TM}} 5.5$ conjugated cyclic RGD peptide could be used to visualize subcutaneously (s.c.) inoculated integrin-positive tumors (Figure 2) (47). In vivo imaging with a prototype three-dimensional (3-D) small-animal imaging system visualized subcutaneously U87MG glioblastoma xenograft with a broad range of concentrations of fluorescent probe administered via the tail vein. The intermediate dose $(0.5 \mathrm{nmol})$ produced better tumor contrast than the high dose $(3 \mathrm{nmol})$ and the low dose $(0.1 \mathrm{nmol})$ during $30 \mathrm{~min}$ to $24 \mathrm{~h}$ p.i., because of partial self-inhibition of receptor-specific tumor uptake at high dose and the presence of significant amount of background fluorescence at low dose, respectively. Subsequently, Wang et al. also reported optical imaging of tumor xenografts using an integrin $\alpha_{v} \beta_{3}$-targeted peptide c(KRGDf) labeled with fluorescent dyes Cy5.5 and IRDye800 $(48,49)$. In vitro, the peptide-dye conjugates bound specifically to integrin $\alpha_{v} \beta_{3}$-positive tumor cells. When administered intravenously (i.v.) into mice, dynamic imaging revealed that Cy5.5-c(KRGDf) was rapidly taken up by KS1767 tumor (human Kaposi's sarcoma) after bolus injection, and the uptake of Cy5.5-c(KRGDf) in tumor regions were linearly increased with a dose of up to $1.5 \mathrm{nmol} / \mathrm{mouse}$ (possibly integrin receptor saturation above this dose). However, the tumor-to-background ratio was modest, and very low contrast was observed in another integrin $\alpha_{4} \beta_{3}$-positive M21 human melanoma tumor.

Burnett et al. (50) also reported the use of integrin $\alpha_{v} \beta_{3^{-}}$ targeted optical probes both in vitro and in vivo. A series of aliphatic carbamate derivatives of the nonpeptide integrin antagonists were synthesized, and the binding affinity was determined by enzymelinked immunoabsorbent assay (ELISA) and cell adhesion inhibition assays. They observed that a hydrophobic carbamate linker increased the binding affinity of the parent compound for integrin $\alpha_{v} \beta_{3}$ by 2- to 20 -fold and demonstrated that the probe with a neopentyl linker exhibited increased binding affinity and significant tumor cell uptake in vitro as well as specific tumor accumulation and retention in vivo. Very recently, Achilefu et al. (51) discovered that

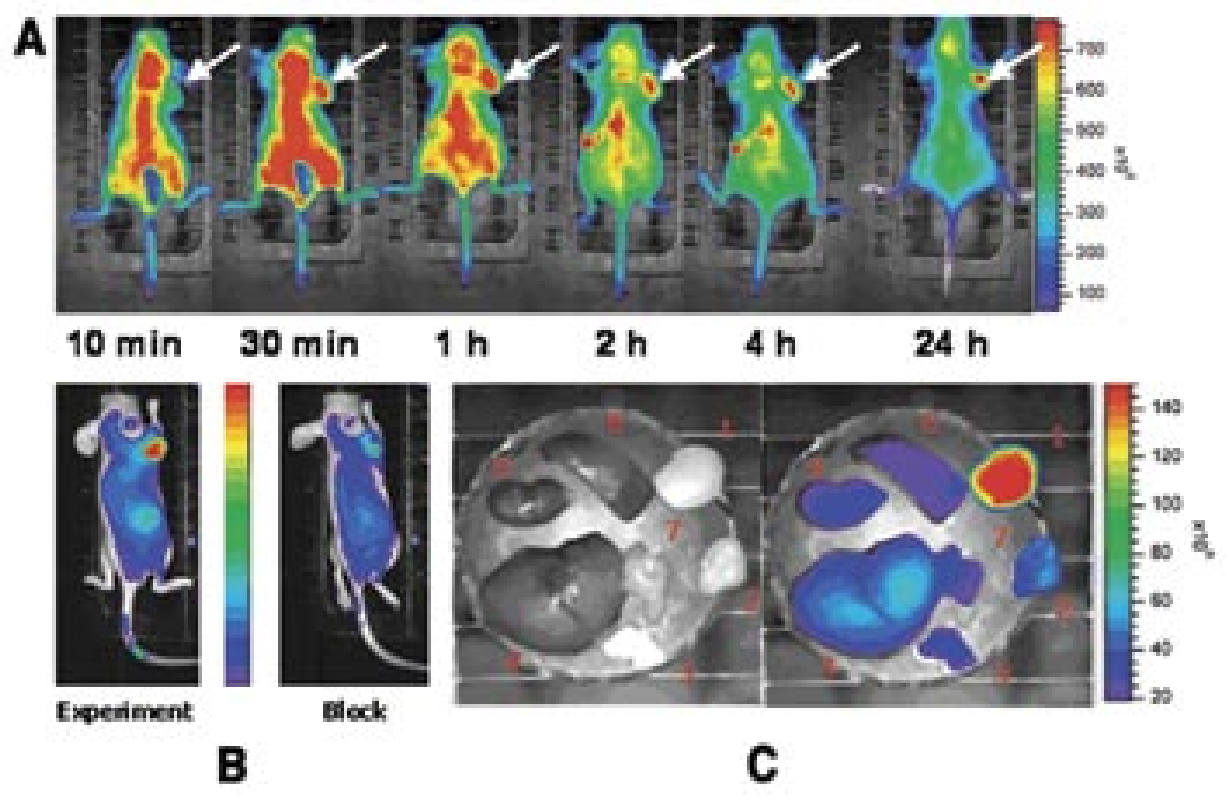

Figure 2. In vivo and ex vivo optical imaging of tumor xenografts. (A) In vivo near-infrared (NIR) fluorescence imaging of subcutaneously (s.c.) U87MG tumor bearing athymic nude mice after intravenously (i.v.) injection of arginine-glycine-aspartic acid (RGD)-Cy5.5 conjugate ( $3 \mathrm{nmol}$ ). (B) Representative NIR images $\left(60^{\circ}\right.$ mounting angle) of tumor mice demonstrating blocking of RGD-Cy5.5 ( $\left.0.5 \mathrm{nmol}\right)$ uptake in the tumors by co-injection of $10 \mathrm{mg} / \mathrm{kg}$ mice body weight of $\mathrm{c}(\mathrm{RGDyK})$. Pseudocolor fluorescence images of tumor bearing mice were acquired $4 \mathrm{~h}$ postinjection (p.i.) of RGD-Cy5.5 (left, experiment) or RGD-Cy5.5 + RGD (right, block). (C) Representative images of dissected organs of a tumor mouse sacrificed 4 h p.i. 1, U87MG tumor; 2 , muscle; 3, pancreas; 4, liver; 5, kidney; 6, spleen; 7, lung. Adapted from Reference 47. conjugating a presumably inactive linear hexapeptide GRDSPK with an NIR carbocyanine molecular probe yielded Cyp-GRD that targets integrin $\alpha_{w} \beta_{3}$-positive tumors. In vivo, Cyp-GRD selectively accumulated in tumors. Blocking studies with $c(R G D F)$ inhibited the uptake of Cyp-GRD, suggesting that both compounds target the same site of integrin $\alpha_{v} \beta_{3}$. Surprisingly, neither a Cypate-labeled linear RGD peptide nor an ${ }^{111}$ In-labeled DOTA-GRD conjugate exhibited specific tumor targeting. Ex vivo redox studies suggested that the probe accumulation level in integrin $\alpha_{v} \beta_{3}$-positive tumors might be correlated with mitochondrial NADH concentration. More experiments need to be carried out to fully understand this phenomenon, and a docking experiment is needed to confirm whether Cyp-RGD actually binds to the RGD binding domain in integrin $\alpha_{v} \beta_{3}$.

Quantum dots (QDs) with size- and composition-tunable fluorescence emission have high quantum yields and photostability suitable for optical imaging and multiplexing (52). We (53) labeled QD705 (emission wavelength $705 \mathrm{~nm}$ ) with a monomeric RGD peptide $c(R G D y K)$, and the resulting conjugate $Q D 705-R G D$ was tested for in vitro staining of several cancer cell lines, ex vivo tissue staining, and in vivo tumor targeting. The in vitro cell staining experiments demonstrated the specific integrin targeting ability of QD705-RGD, and the fluorescence intensity correlated well with the integrin level of the cell lines. The tumor signal of QD705-RGD in nude mice U87MG xenografts steadily increased during the first several hours and reached a peak at $6 \mathrm{~h}$ (tumor-to-muscle ratio of about 3.6). QD705 had minimal tumor uptake, and no enhancement was found throughout the study as compared to muscle. Most of the injected particles accumulated in the liver, spleen, bone marrow, and lymphatic systems, suggesting that the mononuclear phagocytes of the reticuloendothelial system (RES), which can mediate nonspecific uptake of circulating particulates are involved in the clearance of some of the circulating QD705 and QD705-RGD particles in the mice (54). Based on these results, an approach that takes advantage of the high integrin targeting efficacy of the cyclic RGD peptides, high stability and brightness of $Q D$, and emission wavelength in the NIR window will have great potential in cancer diagnosis and imaging as well as imaging-guided surgery and therapy.

\section{RADIONUCLIDE IMAGING OF INTEGRIN $\alpha_{V} \beta_{3}$ EXPRESSION}

\section{Single Photon Emission \\ Computed Tomography}

As its name suggests (single photon emission), the source of SPECT images are $\gamma$-ray emissions (55). Internal radiation is administered through a low mass amount of pharmaceutical labeled with a radioactive isotope, which is then inhaled, ingested, or injected. The radioactive isotope decays and emits $\gamma$-rays, which can be detected by a $\gamma$-camera. The $\gamma$-camera can be used in planar imaging to obtain two-dimensional (2-D) images, or in SPECT imaging, to obtain 3-D images. The first object that an emitted $\gamma$-photon encounters after exiting the body is the collimator that allows it to travel only along certain directions to reach the detector, to ensure that the 
position on the detector accurately represents the source of the $\gamma$-ray. SPECT imaging has a very low detection efficiency of $<10^{-4}$ times the emitted number of $\gamma$-rays because of the use of lead collimators to define the angle of incidence. However, the advantage of SPECT imaging is that it allows simultaneous imaging of multiple radionuclides since $\gamma$-rays emitted from different radioisotopes can be differentiated based on the energy.

Janssen and coworkers (56) studied the in vivo behavior of the radiolabeled dimeric $R G D$ peptide $E[c(R G D f K)]_{2}$ in the subcutaneous $\mathrm{NIH}$ :OVCAR-3 ovarian carcinoma xenograft model in BALB/C nude mice. ${ }^{111} \mathrm{In} / 90 \mathrm{Y}$ and $99 \mathrm{mTC}$ were incorporated through DOTA and hydrazinonicotinamide (HYNIC) chelators, respectively (Figure 3). Tumor uptake was as high as 7.5\% injected dose (ID)/g ( ${ }^{111} \mathrm{In}-D O T A-$ $\left.\mathrm{E}[\mathrm{c}(\mathrm{RGDfK})]_{2}\right)$ at $2 \mathrm{~h}$ p.i. or $6.0 \% \mathrm{ID} / \mathrm{g}\left({ }^{9} \mathrm{mTC}-\mathrm{HYNIC}-\mathrm{E}-[\mathrm{c}(\mathrm{RGDfK})]_{2}\right)$ at $1 \mathrm{~h}$ p.i.. A single injection of ${ }^{90 Y-D O T A-E}[\mathrm{c}(\mathrm{RGDfK})]_{2}$ at $37 \mathrm{MBq}$ in mice with small subcutaneous tumors caused a significant growth delay as compared with control mice. However, increasing the number of injections did not improve the therapeutic efficacy $(57,58)$. Moreover, the prominent renal uptake limits its potential in clinical applications. Multimeric RGD peptides with even higher receptor affinity and longer tumor retention time might be more suitable for clinical translation.

RP748, an ${ }^{111}$ In-labeled quinolone that binds to integrin $\alpha_{v} \beta_{3}$ with high affinity, was recently studied both in vitro and in vivo to track injury-induced vascular proliferation in rodents (59). This tracer exhibits selective binding to activated $\alpha_{v} \beta_{3}$ integrin, and activation of integrin $\alpha_{v} \beta_{3}$ by $\mathrm{Mn}^{2+}$ led to increased cell binding. RP748 was then injected into mice at 1, 3, or 4 weeks after left carotid injury, and carotids were harvested for autoradiography. It was found that the relative autographic intensity was higher at 1 and 3 weeks and decreased significantly by 4 weeks after injury. Carotid $\alpha_{v}$ and $\beta_{3}$ integrin expression peaked at 1 week and decreased by 4 weeks after injury. The proliferation index obtained from Ki67 staining exhibited a temporal pattern that correlates to RP748 uptake. In vivo imaging of this radiolabeled integrin $\alpha_{v} \beta_{3}$-targeting agent was performed in a canine model of postinfarction angiogenesis (60). Serial in vivo dual-isotope SPECT imaging with RP748 and $99 \mathrm{mTC}-\mathrm{MIBI}$ demonstrated focal radiotracer uptake in hypoperfused regions where angiogenesis was stimulated. A 4-fold increase in myocardial radiotracer uptake in the infarct region was observed, which was confirmed by histological staining of $\alpha_{v} \beta_{3}$ integrin. These results demonstrated in vivo imaging of vascular cell proliferationassociated states, whether focal, as in postangioplasty re-stenosis, or diffuse, as in pulmonary hypertension, which may lead to better understanding of pathophysiology, development of novel paradigms for management of cardiovascular disease, as well as better risk stratification of patients following myocardial infarction.

\section{Positron Emission Tomography}

To date, most of integrin targeted PET studies have been focused on the radiolabeling of RGD peptide antagonists of integrin $\alpha_{4} \beta_{3}$ due to its high binding affinity (nanomolar to subnanomolar range for monomeric and multimeric RGD peptides) (61-64). For early lesion detection, acquisition of higher count statistics is particularly valuable for detecting the fewest possible cells per unit volume with the least amount of radioactivity. The sensitivity of PET is very high $\left(10^{-11}-10^{-12} \mathrm{M}\right)$, and there is no depth limitation for detecting tumor signal $(1,65)$. Therefore, PET imaging of tumor integrin expression is the most extensively studied among all the modalities described above. The current status of RGDbased PET probe development is reviewed next.

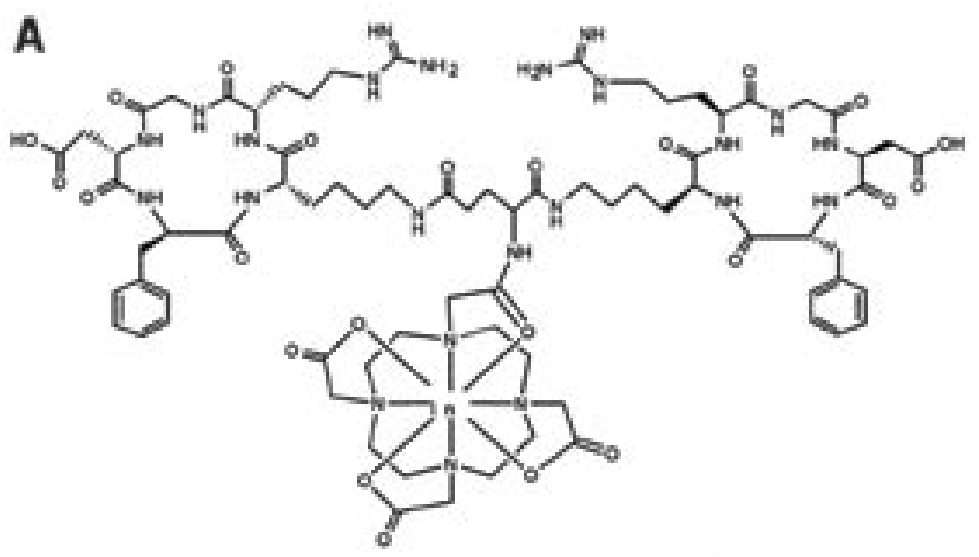

\section{${ }^{18}$ F-Labeled RGD Peptides}

Monomeric RGD peptide $c(R G D y V)$ was first labeled by Haubner et al. (61) with ${ }^{125}$. This tracer had rapid tumor washout and unfavorable hepatobiliary excretion due to its high lipophilicity, which limited its further application. Glycosylation on the lysine side chain of a similar RGD peptide $c($ RGDyK) decreased the lipophilicity and the hepatic uptake (66). Another glycopeptide based on c(RGDfK) was then labeled with ${ }^{18} \mathrm{~F}$ via $2-[18 \mathrm{~F}]$ fluoropropionate prosthetic group, and the resulting [18 $\mathrm{F}]$ galacto-RGD (Figure $4 \mathrm{~A}$ ) exhibited integrin $\alpha_{v} \beta_{3}$-specific tumor uptake in integrin-positive M21 melanoma xenograft model $(62,67,68)$. It was also demonstrated that $\left[{ }^{18} \mathrm{~F}\right]$ galacto-RGD is sensitive enough to visualize $\alpha_{v} \beta_{3}$ expression resulting exclusively from the tumor vasculature using an A431 human squamous

B

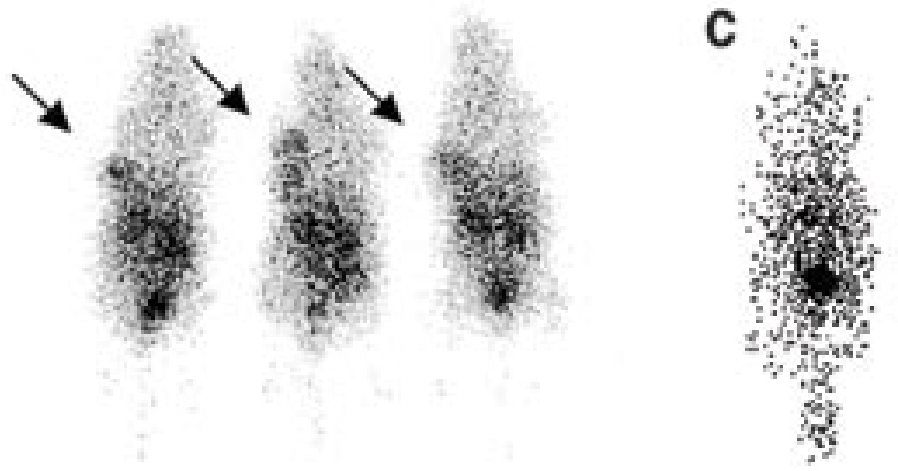

Figure 3. In vivo tumor imaging using ${ }^{111}$ In-labeled tracer. (A) Structure of ${ }^{111}$ In-DOTA-E- $[\mathrm{c}(\mathrm{RGDfK})]_{2}$. (B) Scintigraphic image of three athymic BALB/c mice with a subcutaneous NIH:OVCAR-3 tumor $2 \mathrm{~h}$ after injection of $1.8 \mathrm{MBq}$ ${ }^{111}$ In-DOTA-E- $[\mathrm{c}(\mathrm{RGDfK})]_{2}$, tumors are pointed out by arrows. Prominent activity accumulations in the kidneys, liver, and intestines are also obvious. (C) Mouse injected with $1.8 \mathrm{MBq}$ of the ${ }^{111}$ In-labeled scrambled peptide DOTA-E-[c(RGKfD) $]_{2}$ showed no significant tumor uptake. Adapted from Reference 56. cell carcinoma model, in which the tumor cells are integrin negative. Quantitative analysis showed that uptake of $\left[{ }^{18} \mathrm{~F}\right]$ Galacto-RGD in the melanoma model is related to $\alpha_{v} \beta_{3}$ expression as determined by Western blot analyses. Initial clinical trials in healthy volunteers and a limited number of cancer patients revealed that this tracer can be safely administered to patients and is able to delineate certain lesions that are integrin-positive with reasonable contrast $(62,69)$. Therefore, this approach may help in planning and optimizing therapeutic strategies targeting the $\alpha_{v} \beta_{3}$ integrin.

Despite the successful translation of [ $\left.{ }^{18} \mathrm{~F}\right]$ Galacto-RGD into clinical trials, several key issues remain to be resolved. (i) Tumor targeting efficacy-as a monomeric RGD peptide tracer, it has relatively low integrin binding affinity and only modest tumor standard uptake values (SUVs). Therefore, tumors with low integrin expression level may not be detectable. (ii) Pharmacokinetics-although glycosylation improved the pharmacokinetic behavior of the tracer to a 
certain degree, prominent activity accumulation in the liver, kidneys, spleen, and intestines was still observed in both preclinical models and human studies, which makes it difficult to visualize lesions in the abdomen. (iii) Quantification of integrin density-it is unclear whether the tumor contrast from [18F]galacto-RGD/PET is a true reflection of tumor integrin $\alpha_{v} \beta_{3}$ expression level in vivo. In the preclinical M21/M21-L model, there is moderate correlation between tumor/background ratios (obtained from PET) and relative integrin $\alpha_{v} \beta_{3}$ expression level (from Western blot analyses) (Figure 4, B and C). In the clinical trial, the kinetic modeling was carried out using a two-tissue compartment model for the tumors and a one-tissue compartment model for the muscle. The tracer uptake does not seem to correlate with melanoma patient tumor grading and the tumor metastatic potential. As shown in Figure 4D, a patient with malignant melanoma stage IV and multiple metastases in the liver, skin, and lower abdomen showed virtually no uptake of [18F]Galacto$R G D$, while in Figure 4E, a patient with malignant melanoma stage $\mathrm{IIIb}$ and a solitary lymph node metastasis in the right axilla can be detected.

Sutcliffe-Goulden et al. (70) labeled a linear RGD peptide with ${ }_{18}^{18}$ via solid-phase synthesis. Unfortunately, low metabolic stability and low avidity of the linear RGD peptide did not give tumor contrast. RGD peptides have also been labeled with ${ }^{18} \mathrm{~F}$ through electrophilic substitution method (71). The direct fluorination strategy resulted in multiple side products that were difficult to purify by high-performance liquid chromatography (HPLC). The low specific activity of the carrier-added product, in particular, makes such tracers unsuitable for in vivo integrin imaging.

We labeled $c(R G D y K)$ with ${ }^{18} \mathrm{~F}$ through a fluorobenzoyl prosthetic group (Figure 5) $(26,29,72)$. The resulting [18F]FB-RGD had good tumor-to-blood and tumor-to-muscle ratios but also rapid tumor washout and unfavorable hepatobiliary excretion, making it only suitable for visualizing lesions above the liver (e.g., breast cancer, head and neck cancer, and brain tumor). Rather than introducing an amino sugar moiety to increase the hydrophilicity $(62,67)$, an amphiphilic polyethylene glycol (PEG) linker (MW = 3400) was incorporated to improve the pharmacokinetics $(26,73)$. PEGylation significantly prolonged tumor retention without compromising the desired rapid clearance of radioactivity from liver and kidneys, yet it also reduced the receptor binding affinity of the RGD peptide. The overall effect is that the tumor uptake is comparable to the unmodified monomeric RGD peptide but with improved pharmacokinetics. One disadvantage is that PEG is not a monodisperse compound, which makes complete characterization of the tracer more difficult.

Since $c($ RGDyK) gives better in vivo imaging results than $c(R G D f K)$, due to its increased hydrophilicity (D-Tyr is more hydrophilic than D-Phe), which gives lower liver uptake, and the bent conformation of both peptides has been optimized to fit into the deep cleft between the $\alpha$ and $\beta$ units of integrin $\alpha_{v} \beta_{3}$, it is unlikely that one can further improve integrin affinity and selectivity of the monomeric RGD peptide by fine-tuning the pentapeptide configuration $(22,74)$. Polyvalency effects have been applied to develop dimeric and multimeric RGD peptides, with repeating cyclic pentapeptide units connected by glutamates $(28,56-58,63,75,76)$. Indeed, the dimeric RGD peptide $E[c(R G D y K)]_{2}$ exhibited one order of magnitude higher binding affinity than the corresponding monomer $c(R G D y K)$. $\left[{ }^{18} \mathrm{~F}\right] \mathrm{FB}-\mathrm{E}[\mathrm{C}(\mathrm{RGDyK})]_{2}$ (abbreviated as [ $\left.{ }^{18} \mathrm{~F}\right] \mathrm{FRGD}$ ) (Figure 6A) had predominant renal excretion and almost twice as much tumor uptake in the same animal model as compared to the monomeric tracer $\left[{ }^{18 F}\right]$ FB-c(RGDyK). The synergistic effect of polyvalency (77) and improved pharmacokinetics may be responsible for the excellent imaging characteristics of [18F]FRGD2 (Figure 6B).

In order to quantify integrin $\alpha_{v} \beta_{3}$ expression level in vivo, graphical analyses of the dynamic microPET scans in several tumor xenograft models, such as glioma, breast cancer, prostate cancer, and non-small cell lung cancers were performed (78). The Logan

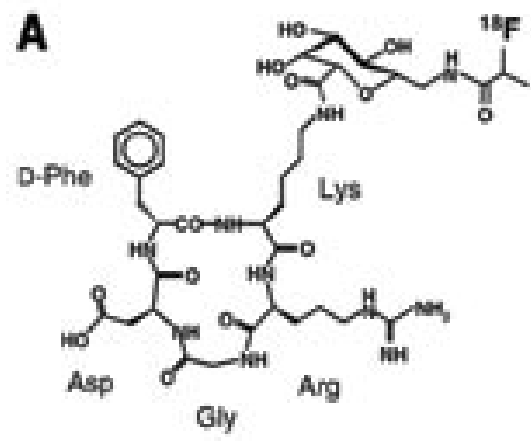

D

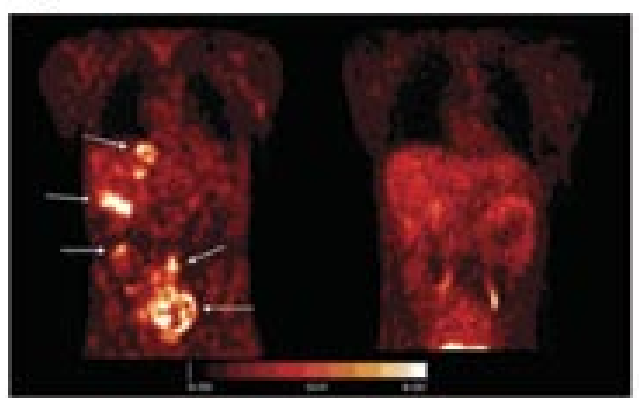

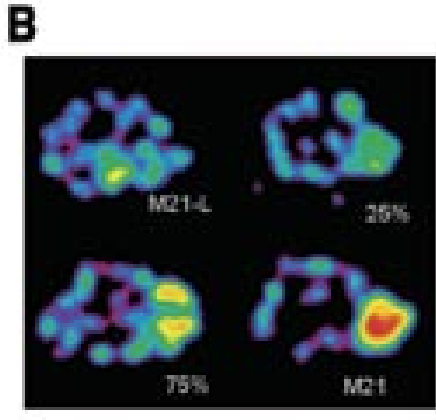
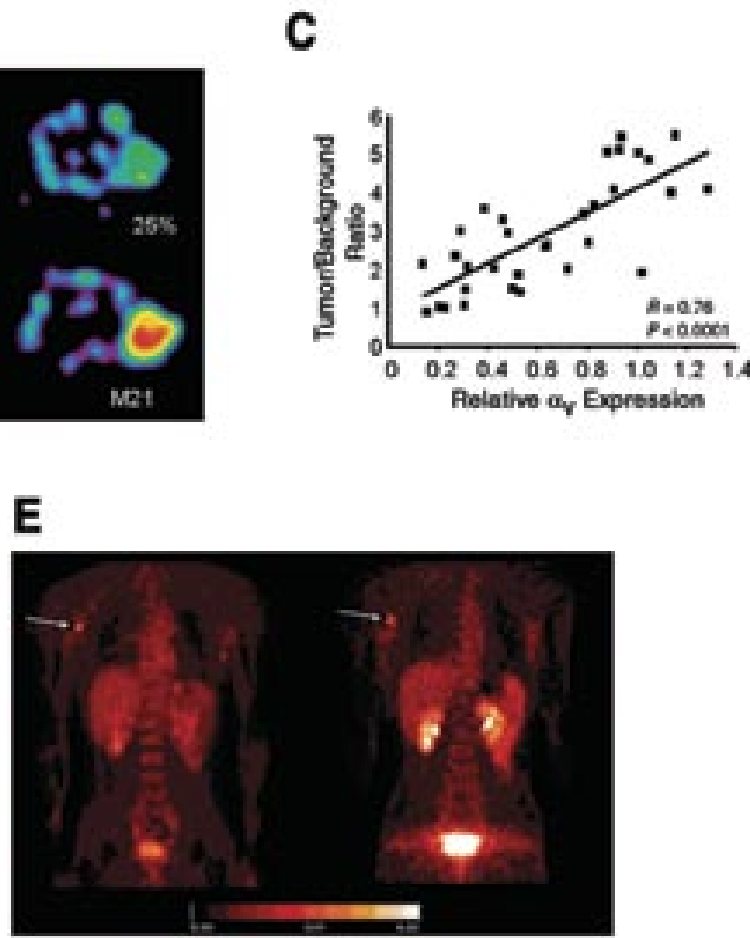

Figure 4. Integrin $\alpha_{v} \beta_{3}$ expression imaging in cancer patients using an RGD-based tracer. (A) Structure of [18F] Galacto-RGD. (B) Transaxial images of nude mice bearing tumors with increasing amounts of $\alpha_{\mathrm{v}} \beta_{3}$-positive M21 cells (0\% [M21-L], 25\%, 75\%, and 100\% [M21]) 90 min postinjection (p.i.) obtained from a small-animal positron emission tomography (PET) scanner show increasing tracer uptake in the tumor. (C) The correlation between tumor/background ratios (obtained from PET) and relative integrin $\alpha_{\mathrm{v}} \beta_{3}$ expression (obtained from Western blot analyses). (D) A patient with malignant melanoma stage IV and multiple metastases in the liver, skin, and lower abdomen (arrows) showed marked uptake of [18F]FDG (left panel) but virtually no uptake of [18F] Galacto-RGD (right panel) using a clinical PET camera. (E) A patient with malignant melanoma stage IIIb and a solitary lymph node metastasis in the right axilla can be detected by both $\left[{ }^{18} \mathrm{~F}\right]$ FDG (left panel) and $\left[{ }^{18} \mathrm{~F}\right]$ Galacto-RGD (right panel). RGD, arginine-glycine-aspartic acid. Adapted from Reference 62. 
plot (79) (Figure 6C) gave better fit than the Patlak analysis (80), reflecting the reversible binding characteristics of [ $\left.{ }^{18} \mathrm{~F}\right] \mathrm{FRGD} 2$ Since ${ }^{125}$-echistatin forms a sodium dodecyl sulfate (SDS)-stable complex with integrin $\alpha_{v} \beta_{3}$ (resistant to $0.6 \%$ SDS) in the absence of chemical cross-linkers, reducing conditions and heating (81), the tumor integrin density can be quantified by SDS polyacrylamide gel electrophoresis (SDS-PAGE)/autoradiography using 125/-echistatin as radioligand. The binding potential (BP) thus calculated from the Logan plot correlated well with the receptor density measured from receptor autoradiography (Figure 6D). Most importantly, at late time points when most of the nonspecific binding had been cleared, the tumor-to-background ratio also had a linear relationship with the tumor integrin levels (Figure 6F), thus making it possible to quantify tumor integrin expression level in vivo with static PET scans and $\left[{ }^{18} \mathrm{~F}\right] F R G D 2$. Whether this tracer [ $\left.{ }^{18} \mathrm{~F}\right] \mathrm{FRGD} 2$ will be translated into the clinic to correlate between tumor-to-background ratios or SUVs and tumor integrin expression level remains to be determined.

The initial clinical trial of [18 $\mathrm{F}]$ Galacto-RGD boasts promising future of RGD-based PET tracer for in vivo tumor imaging. This tracer gives good contrast in most regions of the body except for the urogenital tract and the liver and spleen, even though the tracer itself is not quite optimal. Multimeric RGD peptides have been reported to exhibit increased binding affinities in vitro and improved tumor accumulation and tumor-to-background ratios in preclinical rodent models as compared with the monomeric compounds $(28,58,63,64,78)$. Therefore, it is necessary to perform a side-by-side comparison to determine whether multimeric RGD-based tracers such as [18F]FRGD2 may exhibit more specific and more sensitive tumor targeting in both the preclinical rodent model and in clinical trials. It is very likely that the multimeric ligand approach will be used for performance optimization of RGD-based PET tracer development.

\section{${ }^{64} \mathrm{Cu}$-Labeled RGD Peptides}

For PET imaging of integrin $\alpha_{v} \beta_{3}$ expression, ${ }^{18} \mathrm{~F}$-labeled RGD peptides will likely be the first choice, since $\left[{ }^{18} \mathrm{~F}\right] \mathrm{F}$ - is readily available from most medical cyclotron facilities. In addition to ${ }^{18} \mathrm{~F}$. labeled RGD peptides, ${ }^{64} \mathrm{Cu}$ - and ${ }^{86} \mathrm{Y}$-labeled RGD peptides are also of considerable interest. ${ }^{64} \mathrm{Cu}\left[\mathrm{t}_{1 / 2}=12.7 \mathrm{~h} ; \beta^{+}=655 \mathrm{keV}(19 \%)\right.$; $\beta-=573 \mathrm{keV}(40 \%)]$ is an attractive radionuclide for both PET imaging and targeted radiotherapy of cancer (82) while ${ }^{86} \mathrm{Y}\left(\mathrm{t}_{1 / 2}=\right.$ $14.7 \mathrm{~h}$ ) is usually used as a substitute of ${ }^{90} \mathrm{Y}$ for pharmacokinetics and dosimetry studies (83). PET imaging of tumors with low doses of ${ }^{64} \mathrm{Cu}$-labeled RGD peptides could also be utilized to determine individual radiation dosimetry prior to therapy with either high dose ${ }^{64} \mathrm{Cu}$ - or ${ }^{67} \mathrm{Cu}$-labeled RGD peptides.

We initially labeled the DOTA-c(RGDyK) conjugate with ${ }^{64} \mathrm{Cu}$ for breast cancer imaging (29). The radiotracer exhibited moderate tumor uptake with prominent liver and kidney retention. The PEGylated analog, ${ }^{64} \mathrm{Cu}-\mathrm{DOTA}-\mathrm{PEG}-\mathrm{c}(\mathrm{RGD}$ yK) showed significantly reduced hepatic activity accumulation, higher renal uptake

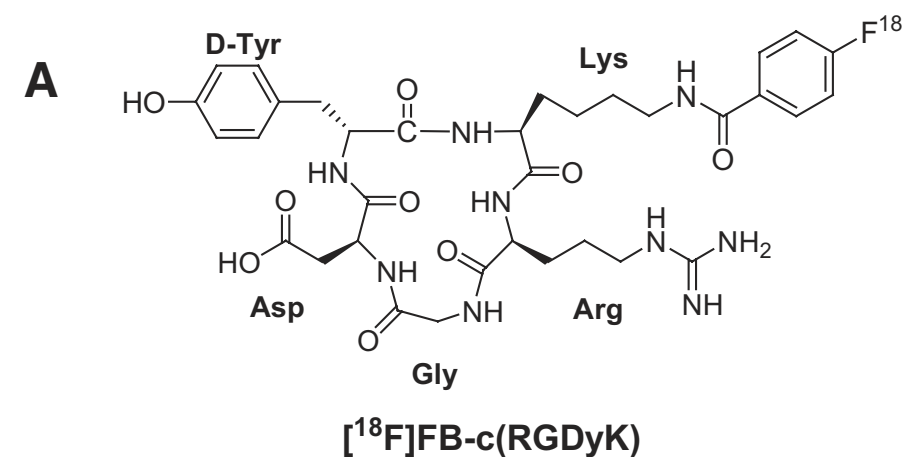

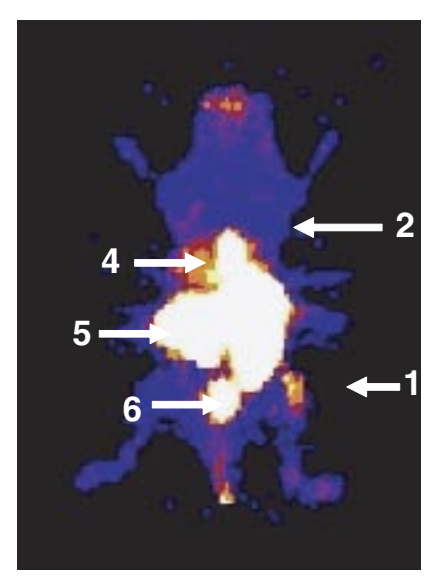

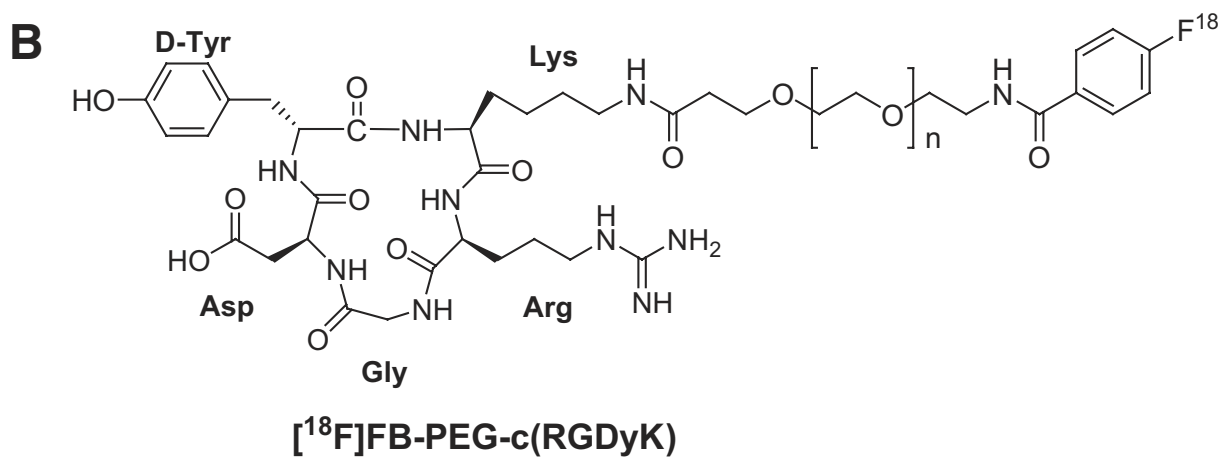

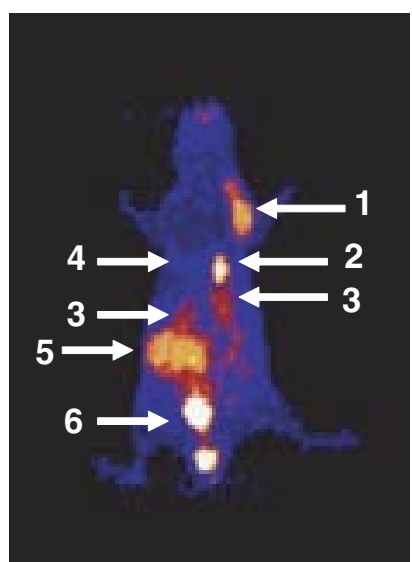

Figure 5. PEGylation improves the in vivo kinetics of ${ }^{18} \mathrm{~F}-$ labeled RGD peptides. (A) Structure of $\left[{ }^{18} \mathrm{~F}\right] \mathrm{FB}-\mathrm{RGD}$ and two-dimensional (2-D) projection microPET image of U87MG tumor-bearing mouse $60 \mathrm{~min}$ after injection of [18F]FB-RGD. (B) Structure of [18F]FBPEG-RGD (PEG M.W. = 3400) and 2-D projection image of U87MG tumor-bearing mouse 60 min after injection of [18F]FB-PEGRGD. 1, U87MG tumor; 2, gallbladder; 3, kidney; 4, liver; 5, intestines; 6, bladder; RGD, arginine-glycine-aspartic acid; PET, positron emission tomography. 
at early time points, but more rapid clearance compared with ${ }^{64} \mathrm{Cu}$ DOTA-c(RGDyK) (84). Although PEGylation at the lysine side chain reduced the integrin binding affinity of the RGD peptide, the tumor activity accumulation was virtually unaltered. However, the suboptimal tumor uptake and retention of this PEGylated tracer limited its further application for receptor radionuclide therapy.

Dimeric RGD peptides were then labeled with ${ }^{64} \mathrm{Cu}$, and their tumor targeting efficacy in murine xenograft models was tested (Figure 7A) (28). At all time points, activity accumulation of ${ }^{64} \mathrm{Cu}$ DOTA-E[c(RGDyK) $]_{2}$ in tumors was significantly higher than that of the D-Phe analog. Liver uptake of ${ }^{64} \mathrm{Cu}-\mathrm{DOTA}-\mathrm{E}[\mathrm{C}(\mathrm{RGDyK})]_{2}$ was lower than the D-Phe derivative ${ }^{64} \mathrm{Cu}-\mathrm{DOTA}-\mathrm{E}[\mathrm{c}(\mathrm{RGDfK})]_{2}$ at early time points but the difference became marginal over time. Overall, ${ }^{64} \mathrm{Cu}-\mathrm{DOTA}-\mathrm{E}[\mathrm{c}(\mathrm{RGDyK})]_{2}$ yielded better PET images in orthotopic MDA-MB-435 bearing mice than did ${ }^{64} \mathrm{Cu}-\mathrm{DOTA}-\mathrm{E}[\mathrm{C}(\mathrm{RGDFK})]_{2}$, most likely attributed to the increased hydrophilicity of D-Tyr over D-Phe. Both dimeric peptides showed better tumor retention than the previously tested monomeric RGD counterparts, presumably because of bivalency and the increase in apparent molecular size. In both cases, the tumor uptake can be efficiently blocked by injection of the unlabeled RGD peptide. PEGylated RGD dimer ${ }^{64} \mathrm{Cu}$-DOTA-
PEG-E $[c(R G D y K)]_{2}$ had similar blood clearance, more rapid renal clearance, and significantly reduced hepatic uptake as compared with ${ }^{64} \mathrm{Cu}-\mathrm{DOTA}-\mathrm{E}[\mathrm{c}(\mathrm{RGDyK})]_{2}$ (75). Rapid tumor localization and high tumor-to-background contrast makes ${ }^{64} \mathrm{Cu}$-DOTA-PEG$E[c(R G D y K)]_{2}$ a promising agent for integrin $\alpha_{v} \beta_{3}$-positive tumor imaging. One striking observation is that it accumulated specifically in both primary and metastatic lung tumor lesions (Figure 7B), while FDG only delineates the primary tumor but none of the metastatic sites because of high uptake of FDG in the heart area. However, the significance of this finding may be slightly diluted by the fact that the magnitude of tumor uptake is too low $(<3 \% \mathrm{ID} / \mathrm{g})$ for peptide receptor radiotherapy applications.

Janssen et al. first applied the polyvalency strategy for SPECT imaging using ${ }^{99 \mathrm{~m} T \mathrm{C}}$ and ${ }^{111} \mathrm{In}$-labeled dimeric RGD peptides $(56,58)$. Various reports have since demonstrated that the dimer gives better in vivo kinetics as well as much improved imaging results. Very recently, Wu et al. (64) developed a tetrameric RGD peptide tracer ${ }^{64} \mathrm{Cu}-\mathrm{DOTA}-\mathrm{E}\left(\mathrm{E}[\mathrm{c}(\mathrm{RGDFK})]_{2}\right)_{2}$ (Figure $8 \mathrm{~A}$ ) for integrin $\alpha_{v} \beta_{3}$ imaging in a subcutaneous U87MG glioma xenograft model. The RGD tetramer showed significantly higher integrin binding affinity than the corresponding mono- and dimeric RGD analogs. The radio-
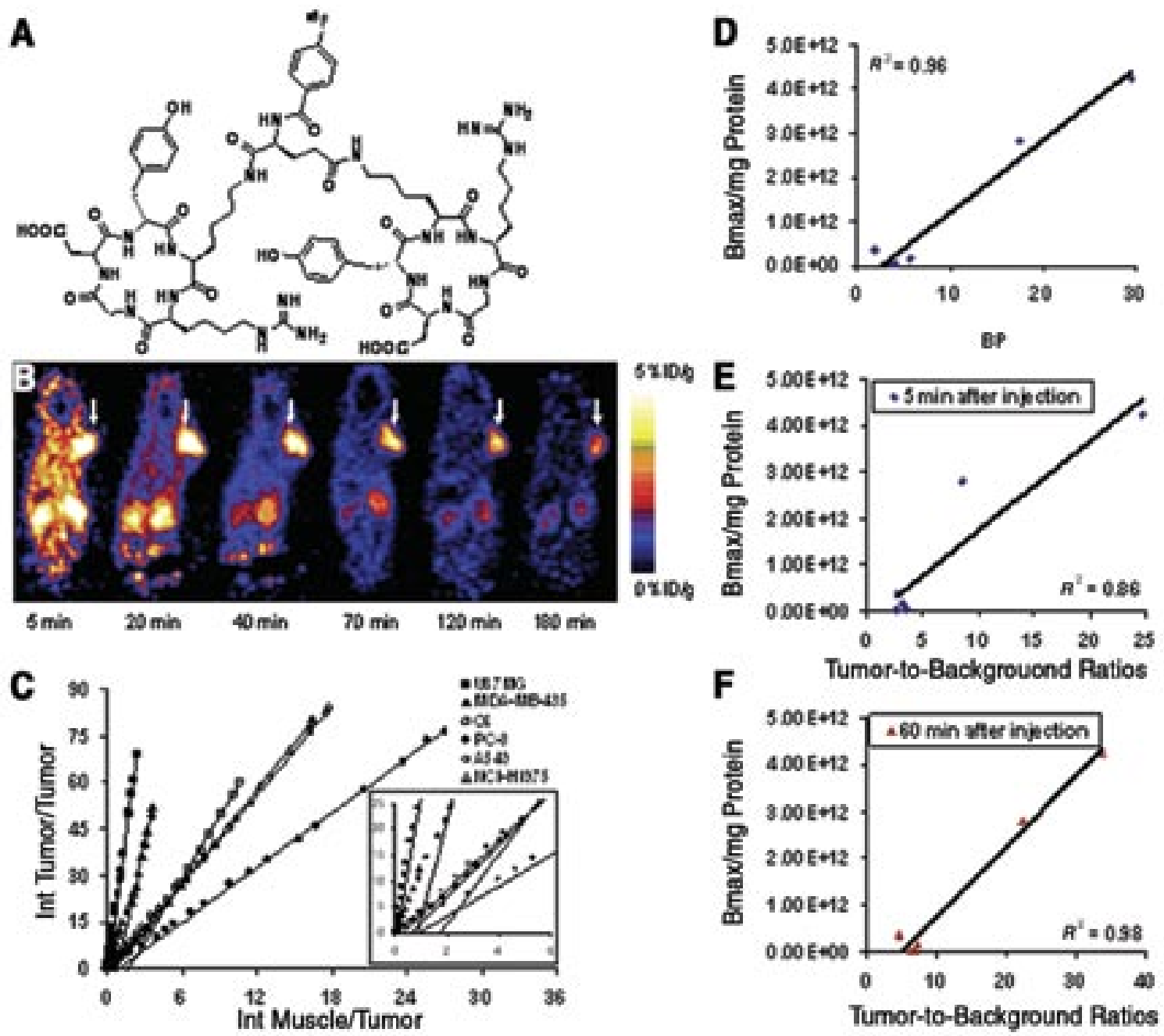

Figure 6. Quantitative imaging of integrin $\boldsymbol{\alpha}_{\mathrm{v}} \boldsymbol{\beta}_{3}$ expression in vivo. (A) Structure of [18F]FB-E[c(RGDyK)]2 (abbreviated as [18 F]FRGD2). (B) Dynamic microPET study of U87MG tumor-bearing mouse over $60 \mathrm{~min}$ after injection of [ $\left.{ }^{18} \mathrm{~F}\right] \mathrm{FRGD} 2$, static scans at 120 min and 180 -min time points were also conducted to complete the tracer kinetic study. Decay-corrected whole-body coronal images containing the tumor are shown. (C) Logan plots derived from 60-min dynamic microPET imaging data showed excellent linearity of normalized integrated (Int) tumor activity versus normalized integrated muscle tissue activity effective for $\mathrm{t}>25 \mathrm{~min}$. The curves for $\mathrm{t}<25 \mathrm{~min}$ are shown in the inset. (D) Correlation analysis between tumor tissue receptor density [Bmax/mg protein measured from sodium dodecyl sulfate polyacrylamide gel electrophoresis (SDS-PAGE)/autoradiography using ${ }^{125}$ I-echistatin as the radioligand] versus binding potential (BP; calculated from the Logan plot transformation of dynamic microPET imaging data). (E) Tumor tissue receptor density versus tumor-to-background ratio at 5 min postinjection (p.i.) of [ $\left.{ }^{18} \mathrm{~F}\right]$ FRGD2. (F) Tumor tissue receptor density versus tumor-to-background ratio at $60 \mathrm{~min}$ p.i. of [18 $\left.\mathrm{F}\right] \mathrm{FRGD2}$. PET, positron emission tomography. Adapted from References 63 and 78 
labeled peptide showed rapid blood clearance, predominant renal excretion, significant receptor-mediated tumor uptake, and good contrast in tumor mice. Tumor uptake was rapid and high, and the tumor washout was slow $(9.93 \pm 1.05 \% \mathrm{ID} / \mathrm{g}$ at $30 \mathrm{~min}$ p.i. and 4.56 $\pm 0.51 \% \mathrm{ID} / \mathrm{g}$ at $24 \mathrm{~h}$ p.i.) (Figure $8 \mathrm{~B}$ ). This tracer was metabolically stable. The high integrin avidity and favorable biokinetics make ${ }^{64} \mathrm{Cu}-\mathrm{DOTA}-\mathrm{E}\left(\mathrm{E}[\mathrm{c}(\mathrm{RGDfK})]_{2}\right)_{2}$ a promising agent for peptide receptor radionuclide imaging as well as radiotherapy of integrinpositive tumors.

\section{CONCLUSION AND FUTURE PERSPECTIVE}

Significant advances have been achieved in developing novel probes for multimodality molecular imaging of tumor integrin expression. Small molecules, peptides, peptidomimetic integrin $\alpha_{v} \beta_{3}$ antagonists, and antibodies have been labeled with radioisotopes, superparamagnetic nanoparticles, fluorescent dyes, QDs, and microbubbles for PET, SPECT, MRI, NIR fluorescence, and ultrasound imaging of small animals, mostly tumor models. The nanoparticles or microbubbles used for MRI or ultrasound imaging has relatively large particle sizes (usually $>200 \mathrm{~nm}$ ) and typically can not extravasate from the blood vessels. Therefore, they may only be suitable for tumor vasculature imaging rendering limited potential in the clinic due to less available targets as compared to the small molecule tracers that can extravasate and therefore target
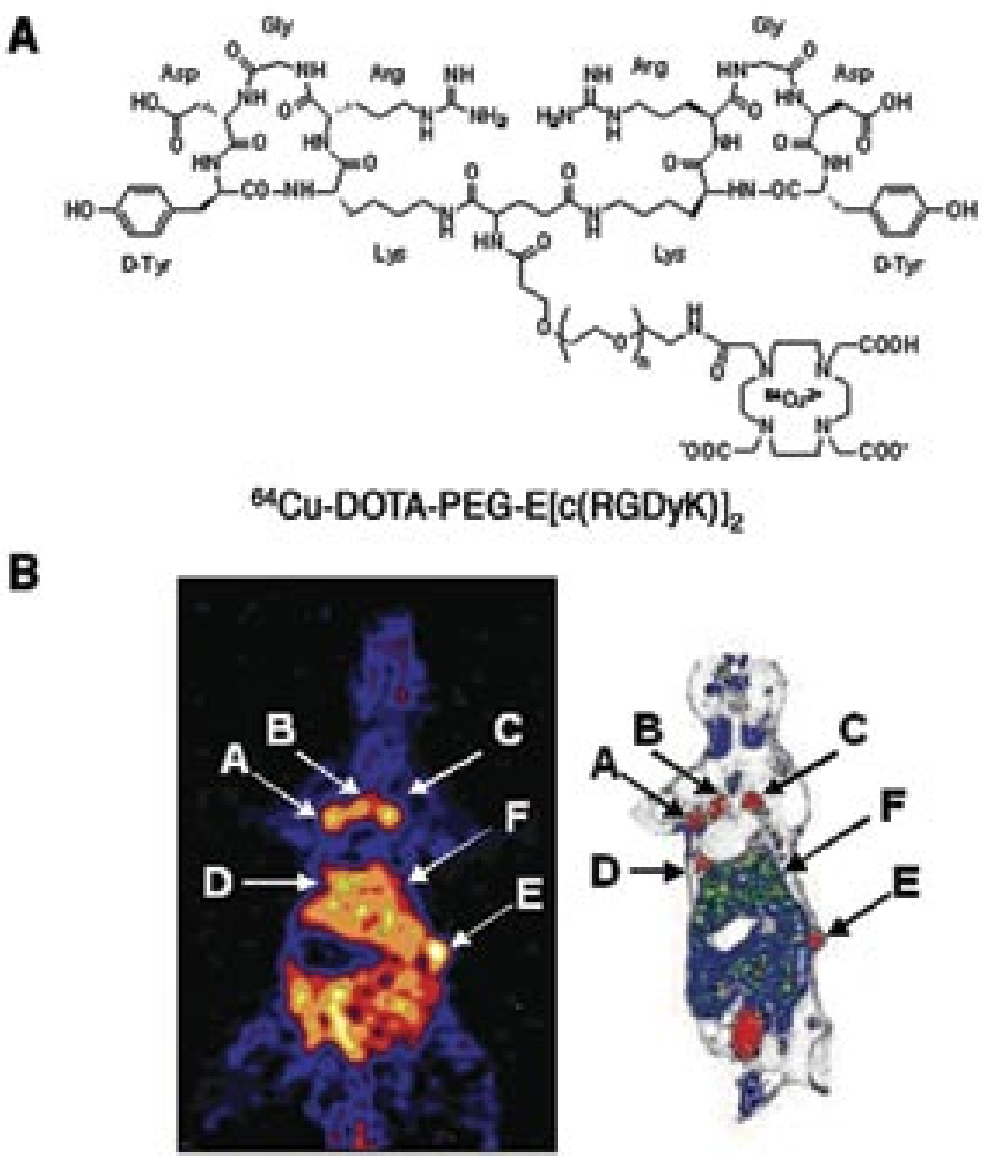

Figure 7. ${ }^{64} \mathrm{Cu}$-labeled tracer for integrin $\alpha_{\mathrm{v}} \beta_{3}$ expression imaging. (A) The structure of ${ }^{64} \mathrm{Cu}$-DOTA-PEG-E[c(RGDyK) $]_{2}$. (B, left panel) coronal image (15-min static scan) of severe combined immunodeficiency (SCID)-bg mouse bearing both subcutaneous and orthotopic NCI-H1975 tumors at $2 \mathrm{~h}$ after injection of ${ }^{64} \mathrm{Cu}-\mathrm{DOTA}-\mathrm{PEG}-\mathrm{E}[\mathrm{c}(\mathrm{RGDyK})]_{2}$. Both primary tumors and metastases are clearly identified. (B, right panel) Whole body digital autoradiograph of a $50-\mu \mathrm{m}$-thick section correlating well with the coronal microPET image shown on the left. (B, panel labels) A, primary orthotopic tumor in the upper lobe of the left lung; B, local metastasis of the primary tumor; C, contralateral lung metastasis; D, metastasis in the diaphragm; E, subcutaneous tumor; F, liver. PET, positron emission tomography. Adapted from Reference 75. not only the tumor vasculature but also the tumor cells. Because of the high sensitivity and adequate spatial and temporal resolution of PET, development of PET probes for integrin expression imaging is currently the most active among all these modalities. [18F]GalactoRGD is already in clinical trials for cancer imaging. ${ }^{18} \mathrm{~F}$-labeled RGD dimer $\left[{ }^{18} \mathrm{~F}\right] \mathrm{FRGD} 2$ may outperform $\left[{ }^{18} \mathrm{~F}\right] \mathrm{Galacto}-\mathrm{RGD}$ because of its higher receptor avidity and more favorable pharmacokinetics as well as the ability to quantify integrin expression in vivo. ${ }^{64} \mathrm{Cu}$ labeled tetramer exhibited high and prolonged tumor retention and rapid liver and kidney clearance resulting in good tumor-to-normal organ ratios, which not only makes this tracer suitable for early lesion detection but also for integrin-targeted radiotherapy. RGD peptides may also be labeled with less common PET isotopes such as ${ }^{124 \mid}$ and ${ }^{86} Y$, which can help guide ${ }^{131} \mid$ and $90 Y-R G D$ therapy, respectively. Radiolabeled antibodies against integrin $\alpha_{v} \beta_{3}$ have not been well studied despite the fact that a humanized monoclonal antibody Vitaxin ${ }^{\circledR}$ is already in phase II clinical trials for treatment of melanoma and prostate cancer patients $(85,86)$. Development of suitably labeled Vitaxin for imaging the pharmacokinetics and pharmacodynamic of the systemically administered antibody or for integrin-targeted radioimmunotherapy may need to be emphasized for future studies.

Despite the fact that $\left[{ }^{18} \mathrm{~F}\right]$ galacto-RGD is already in early clinical trials for documentation of integrin expression in cancer patients, many other relevant integrin $\alpha_{v} \beta_{3}$-specific imaging probes discussed in this review suffer from the slow translation from bench to bedside. Multiple steps in preclinical development, such as pharmacokinetics, dosimetry, imaging feasibility, and investigational new drug (IND)-directed toxicology, are necessary to convert a potential new agent into a diagnostic drug candidate suitable for early clinical testing. Emphasis on highly specific molecular targets and processes has led to products with increased complexity and higher costs of development but smaller market potential. This trend has effectively created a class of agents that investors consider too risky for commercial development, but these agents may have the potential to influence diagnosis and treatment significantly. A general strategy of angiogenesis imaging may thus be more practical in the long run than very specific protein targets (e.g., Her-2/Neu).

Tumor integrin expression imaging has potential clinical applications in many aspects. The first aspect is lesion detection. Despite the clinical success with [18F]FDG/PET imaging, this tracer has several limitations. The tracer can be nonspecifically taken up by several benign conditions such as inflammatory disease, pneumonia, brown fat, muscle, bowel uptake, and granulomatous disease. Also, slow growing indolent tumors may exhibit only a mild increase in glucose metabolism and therefore can be missed by FDG PET $(1,87)$. As most tumor vasculature endothelial cells and many tumor cells express integrin $\alpha_{v} \beta_{3}$, suitably labeled RGD peptides might be a potentially more advantageous surrogate marker than FDG for more sensitive detection or detecting lower tumor burden. The second aspect is patient stratification. Differences in tracer accumulation in various tumor types suggest a great diversity in integrin receptor expression. In light of the differences in receptor expression and tracer accumulation, quantitative imaging of tumor integrin becomes very important as a mechanism to stratify and select patients to enter clinical trials focused on anti-integrin treatment. The third aspect is new drug development and/or validation. Rapid characterization of pharmacokinetics and pharmacodynamics by multimodality in vivo imaging of new tracers or anti-integrin drugs can improve 
data quality, reduce costs, reduce number of animals used, and most importantly, decrease the work-up for new compounds. Fourth is treatment monitoring and optimization. Visualization and quantification of tumor integrin levels by noninvasive molecular imaging can be applied to detect early response to anti-integrin treatment and to elucidate the mechanisms of treatment efficacy underlying integrin signaling, therefore providing important information for treatment optimization. Finally, the fifth aspect is the combination of molecular and functional imaging. As the molecular imaging probes get more specific regarding which leads to a visible signal in only the tumor or other targeted tissue, anatomical and/or functional imaging techniques are needed to identify the exact location of the signal. The combination of molecular and anatomical and/or functional imaging techniques in assessing tumor angiogenesis and in response to antiangiogenic-based therapy will be a powerful tool and the new generation clinical PET-CT and microPET/microCT will likely play a major role in cancer imaging for the years to come.

Tumor integrin $\alpha_{v} \beta_{3}$ expression imaging is given as an example here to demonstrate how molecular imaging can provide a robust platform for understanding the mechanisms of tumor angiogenesis and evaluating the efficacy of novel antiangiogenic therapies. Further progress is needed to improve the sensitivity and resolution of molecular imaging technologies and to develop optimal molecular imaging probes as surrogate markers to pinpoint and monitor specific molecular and cellular actions of angiogenesis inhibitors.
Development of multimodality probes, for example, probes that can give both PET and MRI signals, will be of significant value but are currently unexplored. Other targets besides integrins, such as VEGFR, MMP-2, etc., are also being studied for multimodality in vivo imaging of tumor angiogenesis.

\section{ACKNOWLEDGMENTS}

We apologize to authors whose works were not cited in this review due to space limitations. This work was supported, in part, by National Cancer Institute (NCI) grant R21 CA102123, National Institute of Biomedical Imaging and Bioengineering (NIBIB) grant R21 EB001785, Department of Defense (DOD) Breast Cancer Research Program (BCRP) Concept Award DAMD17-03-1-0752, DOD BCRP IDEA Award W81XWH-04-1-0697, DOD Ovarian Cancer Research Program (OCRP) Award OC050120, DOD Prostate Cancer Research Program (PCRP) New Investigator Award (NIA) DAMD1717-03-1-0143, American Lung Association California (ALAC), the Society of Nuclear Medicine Education and Research Foundation, National Cancer Institute (NCI) Small Animal Imaging Resource Program (SAIRP) grant R24 CA93862, and $\mathrm{NCI}$ In Vivo Cellular Molecular Imaging Center (ICMIC) grant P50 CA114747. The production of Cu-64 at Washington University School of Medicine is supported by the NCI grant R24 CA86307.

\section{COMPETING INTERESTS STATEMENT}

The authors declare no competing interests.

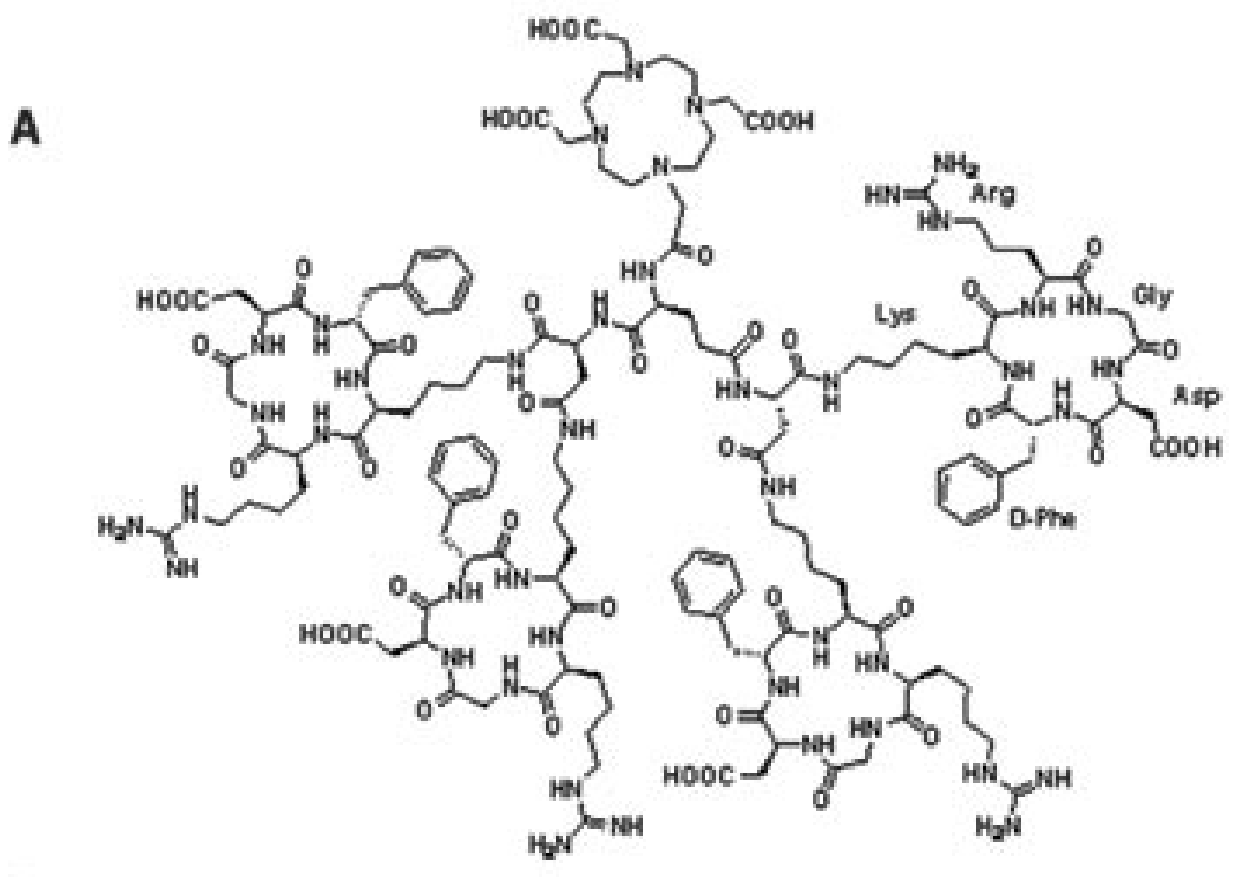

B

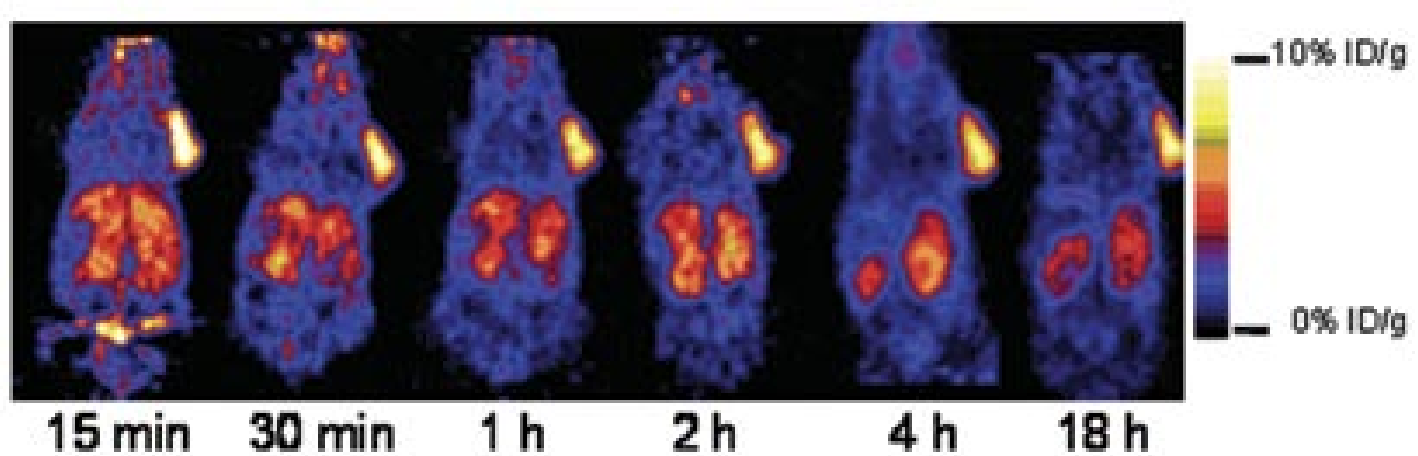

Figure 8. ${ }^{64} \mathrm{Cu}$-labeled tetrameric RGD-based tracer for integrin expression imaging. (A) Structure of DOTA-E $\left(\mathrm{E}[\mathrm{c}(\mathrm{RGDfK})]_{2}\right)_{2}$. $(\mathrm{B}) \mathrm{D}_{\mathrm{C}} \mathrm{Ccay-corrected}$ whole-body coronal microPET images of a nude mouse bearing human U87MG tumor at various time points (10-min static image) after injection of ${ }^{64} \mathrm{Cu}-\mathrm{DOTA}-\mathrm{E}\left(\mathrm{E}[\mathrm{c}(\mathrm{RGDfK})]_{2}\right)_{2}$. PET, positron emission tomography. Adapted from Reference 64. 


\section{REFERENCES}

1. Gambhir, S.S. 2002. Molecular imaging of cancer with positron emission tomography. Nat. Rev. Cancer 2:683-693.

2. Massoud, T.F. and S.S. Gambhir. 2003. Molecular imaging in living subjects: seeing fundamental biological processes in a new light. Genes Dev. 17:545-580.

3. Herschman, H.R. 2003. Molecular imaging: looking at problems, seeing solutions. Science 302:605-608

4. Gross, S. and D. Piwnica-Worms. 2005. Spying on cancer: molecular imaging in vivo with genetically encoded reporters. Cancer Cell 7:5-15

5. Weissleder, R. and U. Mahmood. 2001. Molecular imaging. Radiology 219:316-333.

6. Bergers, G. and L.E. Benjamin. 2003. Tumorigenesis and the angiogenic switch Nat. Rev. Cancer 3:401-410.

7. Ferrara, N. 2002. VEGF and the quest for tumour angiogenesis factors. Nat. Rev. Cancer 2:795-803.

8. Nyberg, P., L. Xie, and R. Kalluri. 2005. Endogenous inhibitors of angiogenesis. Cancer Res. 65:3967-3979.

9. Kerbel, R. and J. Folkman. 2002. Clinical translation of angiogenesis inhibitors Nat. Rev. Cancer 2:727-739.

10. Tucker, G.C. 2003. $a_{v}$ integrin inhibitors and cancer therapy. Curr. Opin. Investig Drugs 4:722-731.

11. Jain, R.K. 2005. Normalization of tumor vasculature: an emerging concept in antiangiogenic therapy. Science 307:58-62.

12. Hanahan, D. and J. Folkman. 1996. Patterns and emerging mechanisms of the angiogenic switch during tumorigenesis. Cell 86:353-364.

13. Friedl, P. and K. Wolf. 2003. Tumour-cell invasion and migration: diversity and escape mechanisms. Nat. Rev. Cancer 3:362-374.

14. Sahai, E. 2005. Mechanisms of cancer cell invasion. Curr. Opin. Genet. Dev. 15:87-96.

15. Egeblad, M. and Z. Werb. 2002. New functions for the matrix metalloproteinases in cancer progression. Nat. Rev. Cancer 2:161-174.

16. Bogenrieder, T. and M. Herlyn. 2003. Axis of evil: molecular mechanisms of cancer metastasis. Oncogene 22:6524-6536.

17. Ruoslahti, E. 1996. RGD and other recognition sequences for integrins. Annu. Rev. Cell Dev. Biol. 12:697-715.

18.Xiong, J.P., T. Stehle, B. Diefenbach, R. Zhang, R. Dunker, D.L. Scott, A Joachimiak, S.L. Goodman, and M.A. Arnaout. 2001. Crystal structure of the extracellular segment of integrin $\alpha_{v} \beta_{3}$. Science 294:339-345.

19. Brooks, P.C., R.A. Clark, and D.A. Cheresh. 1994. Requirement of vascular integrin $\alpha_{v} \beta_{3}$ for angiogenesis. Science 264:569-571.

20. Kumar, C.C. 2003. Integrin $\alpha_{v} \beta_{3}$ as a therapeutic target for blocking tumor-induced angiogenesis. Curr. Drug Targets 4:123-131.

21. Hood, J.D. and D.A. Cheresh. 2002. Role of integrins in cell invasion and migration. Nat. Rev. Cancer 2:91-100.

22. Xiong, J.P., T. Stehle, R. Zhang, A. Joachimiak, M. Frech, S.L. Goodman, M.A. Arnaout, B. Diefenbach, et al. 2002. Crystal structure of the extracellular segment of integrin $\alpha_{4} \beta_{3}$ in complex with an Arg-Gly-Asp ligand. Science 296:151-155.

23. Jin, H. and J. Varner. 2004. Integrins: roles in cancer development and as treatment targets. Br. J. Cancer 90:561-565.

24. Brooks, P.C., S. Stromblad, L.C. Sanders, T.L. von Schalscha, R.T. Aimes, W.G. Stetler-Stevenson, J.P. Quigley, and D.A. Cheresh. 1996. Localization of matrix metalloproteinase MMP-2 to the surface of invasive cells by interaction with integrin $\alpha_{v} \beta_{3}$. Cell 85:683-693.

25. Schmieder, A.H., P.M. Winter, S.D. Caruthers, T.D. Harris, T.A. Williams, J.S. Allen, E.K. Lacy, H. Zhang, et al. 2005. Molecular MR imaging of melanoma angiogenesis with $\alpha_{v} \beta_{3}$-targeted paramagnetic nanoparticles. Magn. Reson. Med. 53:621-627.

26. Chen, X., R. Park, Y. Hou, V. Khankaldyyan, I. Gonzales-Gomez, M. Tohme, J.R. Bading, W.E. Laug, and P.S. Conti. 2004. MicroPET imaging of brain tumor angiogenesis with ${ }^{18} \mathrm{~F}$-labeled PEGylated RGD peptide. Eur. J. Nucl. Med. Mol. Imaging 31:1081-1089.

27. Beck, V., H. Herold, A. Benge, B. Luber, P. Hutzler, H. Tschesche, H. Kessler, M. Schmitt, et al. 2005. ADAM15 decreases integrin $\alpha_{v} \beta_{3} /$ vitronectin-mediated ovarian cancer cell adhesion and motility in an RGD-dependent fashion. Int. J. Biochem. Cell Biol. 37:590-603.

28. Chen, X., S. Liu, Y. Hou, M. Tohme, R. Park, J.R. Bading, and P.S. Conti. 2004 MicroPET imaging of breast cancer $\mathrm{a}_{\mathrm{v}}$-integrin expression with ${ }^{64} \mathrm{Cu}$-labeled $\mathrm{di}$ meric RGD peptides. Mol. Imaging Biol. 6:350-359.

29. Chen, X., R. Park, M. Tohme, A.H. Shahinian, J.R. Bading, and P.S. Conti. 2004. MicroPET and autoradiographic imaging of breast cancer $a_{v}$-integrin expression using ${ }^{18} \mathrm{~F}$ - and ${ }^{64} \mathrm{Cu}$-labeled RGD peptide. Bioconjug. Chem. 15:41-49.

30. Meerovitch, K., F. Bergeron, L. Leblond, B. Grouix, C. Poirier, M. Bubenik, L. Chan, H. Gourdeau, et al. 2003. A novel RGD antagonist that targets both $a_{v} \beta_{3}$ and $\alpha_{5} \beta_{1}$ induces apoptosis of angiogenic endothelial cells on type I collagen. Vascul. Pharmacol. 40:77-89.

31. Qiao, R., W. Yan, H. Lum, and A.B. Malik. 1995. Arg-Gly-Asp peptide increases endothelial hydraulic conductivity: comparison with thrombin response. Am. J. Physiol. 269:C110-117.
32. Haubner, R.H., H.J. Wester, W.A. Weber, and M. Schwaiger. 2003. Radiotracer-based strategies to image angiogenesis. Q. J. Nucl. Med. 47:189-199.

33. Haubner, R. and H.J. Wester. 2004. Radiolabeled tracers for imaging of tumor angiogenesis and evaluation of anti-angiogenic therapies. Curr. Pharm. Des. $10: 1439-1455$

34. Pathak, A.P., B. Gimi, K. Glunde, E. Ackerstaff, D. Artemov, and Z.M. Bhujwalla. 2004. Molecular and functional imaging of cancer: advances in MRI and MRS. Methods Enzymol. 386:3-60.

35. Sipkins, D.A., D.A. Cheresh, M.R. Kazemi, L.M. Nevin, M.D. Bednarski, and K.C. Li. 1998. Detection of tumor angiogenesis in vivo by $a_{v} \beta_{3}$-targeted magnetic resonance imaging. Nat. Med. 4:623-626.

36. Anderson, S.A., R.K. Rader, W.F. Westlin, C. Null, D. Jackson, G.M. Lanza, S.A. Wickline, and J.J. Kotyk. 2000. Magnetic resonance contrast enhancement of neovasculature with $\alpha_{v} \beta_{3}$-targeted nanoparticles. Magn. Reson. Med. 44:433439.

37. Winter, P.M., S.D. Caruthers, A. Kassner, T.D. Harris, L.K. Chinen, J.S. Allen, E.K. Lacy, H. Zhang, et al. 2003. Molecular imaging of angiogenesis in nascent $V x-2$ rabbit tumors using a novel $a_{v} \beta_{3}$-targeted nanoparticle and 1.5 tesla magnetic resonance imaging. Cancer Res. 63:5838-5843.

38. Winter, P.M., A.M. Morawski, S.D. Caruthers, R.W. Fuhrhop, H. Zhang, T.A. Williams, J.S. Allen, E.K. Lacy, et al. 2003. Molecular imaging of angiogenesis in early-stage atherosclerosis with $\alpha_{v} \beta_{3}$-integrin-targeted nanoparticles. Circulation 108:2270-2274

39. Morawski, A.M., G.A. Lanza, and S.A. Wickline. 2005. Targeted contrast agents for magnetic resonance imaging and ultrasound. Curr. Opin. Biotechnol. 16:8992.

40. Ellegala, D.B., H. Leong-Poi, J.E. Carpenter, A.L. Klibanov, S. Kaul, M.E. Shaffrey, J. Sklenar, and J.R. Lindner. 2003. Imaging tumor angiogenesis with contrast ultrasound and microbubbles targeted to $a_{v} \beta_{3}$. Circulation 108:336-341.

41. Leong-Poi, H., J. Christiansen, A.L. Klibanov, S. Kaul, and J.R. Lindner. 2003. Noninvasive assessment of angiogenesis by ultrasound and microbubbles targeted to $a_{\mathrm{v}}$-integrins. Circulation 107:455-460

42. Leong-Poi, H., J. Christiansen, P. Heppner, C.W. Lewis, A.L. Klibanov, S Kaul, and J.R. Lindner. 2005. Assessment of endogenous and therapeutic arteriogenesis by contrast ultrasound molecular imaging of integrin expression. Circulation 111:3248-3254.

43. Shohet, R.V., S. Chen, Y.T. Zhou, Z. Wang, R.S. Meidell, R.H. Unger, and P.A. Grayburn. 2000. Echocardiographic destruction of albumin microbubbles directs gene delivery to the myocardium. Circulation 101:2554-2556.

44. Frangioni, J.V. 2003. In vivo near-infrared fluorescence imaging. Curr. Opin. Chem. Biol. 7:626-634

45. Spibey, C.A., P. Jackson, and K. Herick. 2001. A unique charge-coupled device/ xenon arc lamp based imaging system for the accurate detection and quantitation of multicolour fluorescence. Electrophoresis 22:829-836.

46. Montet, X., V. Ntziachristos, J. Grimm, and R. Weissleder. 2005. Tomographic fluorescence mapping of tumor targets. Cancer Res. 65:6330-6336.

47. Chen, X., P.S. Conti, and R.A. Moats. 2004. In vivo near-infrared fluorescence imaging of integrin $\alpha_{v} \beta_{3}$ in brain tumor xenografts. Cancer Res. 64:8009-8014.

48.Wang, W., S. Ke, Q. Wu, C. Charnsangavej, M. Gurfinkel, J.G. Gelovani, J.L. Abbruzzese, E.M. Sevick-Muraca, and C. Li. 2004. Near-infrared optical imaging of integrin $\alpha_{v} \beta_{3}$ in human tumor xenografts. Mol. Imaging 3:343-351.

49. Sunkuk, K., K. Shi, J.P. Houston, W. Wei, W. Qingping, L. Chun, and E.M. Sevick-Muraca. 2005. Imaging dose-dependent pharmacokinetics of an RGD-fluorescent dye conjugate targeted to $a_{v} \beta_{3}$ receptor expressed in Kaposi's sarcoma. Mol. Imaging 4:75-87.

50. Burnett, C.A., J. Xie, J. Quijano, Z. Shen, F. Hunter, M. Bur, K.C. Li, and S.N. Danthi. 2005. Synthesis, in vitro, and in vivo characterization of an integrin $a_{v} \beta_{3}$-targeted molecular probe for optical imaging of tumor. Bioorg. Med. Chem. 13:3763-3771

51. Achilefu, S., S. Bloch, M.A. Markiewicz, T. Zhong, Y. Ye, R.B. Dorshow, B. Chance, and K. Liang. 2005. Synergistic effects of light-emitting probes and peptides for targeting and monitoring integrin expression. Proc. Natl. Acad. Sci. USA. 102:7976-7981.

52. Michalet, X., F.F. Pinaud, L.A. Bentolila, J.M. Tsay, S. Doose, J.J. Li, G. Sundaresan, A.M. Wu, et al. 2005. Quantum dots for live cells, in vivo imaging, and diagnostics. Science 307:538-544.

53. Cai, W., D. Shin, Y. Wu, O. Gheysens, Q. Cao, S.S. Gambhir, S.X. Wang, and $X$. Chen. RGD peptide-labeled NIR quantum dot for in vivo cancer imaging. Nat. Biotechnol. (Submitted).

54. Rolland, A., B. Collet, R. Le Verge, and L. Toujas. 1989. Blood clearance and organ distribution of intravenously administered polymethacrylic nanoparticles in mice. J. Pharm. Sci. 78:481-484.

55. Peremans, K., B. Cornelissen, B. Van Den Bossche, K. Audenaert, and C. Van de Wiele. 2005. A review of small animal imaging planar and pinhole spect Gamma camera imaging. Vet. Radiol. Ultrasound 46:162-170.

56. Janssen, M.L., W.J. Oyen, I. Dijkgraaf, L.F. Massuger, C. Frielink, D.S. Edwards, M. Rajopadhye, H. Boonstra, et al. 2002. Tumor targeting with radiolabeled $\alpha_{v} \beta_{3}$ integrin binding peptides in a nude mouse model. Cancer Res. 62:6146-6151. 
57. Janssen, M., C. Frielink, I. Dijkgraaf, W. Oyen, D.S. Edwards, S. Liu, M. Rajopadhye, L. Massuger, et al. 2004. Improved tumor targeting of radiolabeled RGD peptides using rapid dose fractionation. Cancer Biother. Radiopharm. 19:399-404.

58. Janssen, M., W.J. Oyen, L.F. Massuger, C. Frielink, I. Dijkgraaf, D.S. Edwards, M. Radjopadhye, F.H. Corstens, and O.C. Boerman. 2002. Comparison of a monomeric and dimeric radiolabeled RGD-peptide for tumor targeting. Cancer Biother. Radiopharm. 17:641-646.

59. Sadeghi, M.M., S. Krassilnikova, J. Zhang, A.A. Gharaei, H.R. Fassaei, L. Esmailzadeh, A. Kooshkabadi, S. Edwards, et al. 2004. Detection of injury-induced vascular remodeling by targeting activated $\alpha_{v} \beta_{3}$ integrin in vivo. Circulation 110:84-90.

60. Meoli, D.F., M.M. Sadeghi, S. Krassilnikova, B.N. Bourke, F.J. Giordano, D.P. Dione, H. Su, D.S. Edwards, et al. 2004. Noninvasive imaging of myocardial angiogenesis following experimental myocardial infarction. J. Clin. Invest. 113:1684-1691.

61. Haubner, R., H.J. Wester, U. Reuning, R. Senekowitsch-Schmidtke, B. Diefenbach, H. Kessler, G. Stocklin, and M. Schwaiger. 1999. Radiolabeled $a_{v} \beta_{3}$ integrin antagonists: a new class of tracers for tumor targeting. J. Nucl. Med. 40:1061-1071.

62. Haubner, R., W.A. Weber, A.J. Beer, E. Vabuliene, D. Reim, M. Sarbia, K.F Becker, M. Goebel, et al. 2005. Noninvasive visualization of the activated $a_{4} \beta_{3}$ integrin in cancer patients by positron emission tomography and [18F]galactoRGD. PLoS Med. 2:e70.

63. Chen, X., M. Tohme, R. Park, Y. Hou, J.R. Bading, and P.S. Conti. 2004. MicroPET imaging of $\alpha_{4} \beta_{3}$-integrin expression with ${ }^{18 F}$-labeled dimeric RGD peptide. Mol. Imaging 3:96-104

64. Wu, Y., X. Zhang, Z. Xiong, Z. Cheng, D.R. Fisher, S. Liu, and X. Chen. 2005 MicroPET imaging of glioma $a_{v}$-integrin expression using ${ }^{64} \mathrm{Cu}$-labeled tetrameric RGD eptide. J. Nucl. Med. 46:1707-1718.

65. Sharma, V., G.D. Luker, and D. Piwnica-Worms. 2002. Molecular imaging of gene expression and protein function in vivo with PET and SPECT. J. Magn Reson. Imaging 16:336-351.

66. Haubner, R., H.J. Wester, F. Burkhart, R. Senekowitsch-Schmidtke, W. Weber, S.L. Goodman, H. Kessler, and M. Schwaiger. 2001. Glycosylated RGD-containing peptides: tracer for tumor targeting and angiogenesis imaging with improved biokinetics. J. Nucl. Med. 42:326-336.

67. Haubner, R., H.-J. Wester, W.A. Weber, C. Mang, S.I. Ziegler, S.L. Goodman, R. Senekowitsch-Schmidtke, H. Kessler, and M. Schwaiger. 2001. Noninvasive imaging of $\alpha_{\vee} \beta_{3}$ integrin expression using ${ }^{18} \mathrm{~F}$-labeled RGD-containing glycopeptide and positron emission tomography. Cancer Res. 61:1781-1785.

68. Haubner, R., B. Kuhnast, C. Mang, W.A. Weber, H. Kessler, H.J. Wester, and M. Schwaiger. 2004. [18F]Galacto-RGD: synthesis, radiolabeling, metabolic stability, and radiation dose estimates. Bioconjug. Chem. 15:61-69.

69. Beer, A.J., R. Haubner, M. Goebel, S. Luderschmidt, M.E. Spilker, H.J. Wester, W.A. Weber, and M. Schwaiger. 2005. Biodistribution and pharmacokinetics of the $\alpha_{v} \beta_{3}$-selective tracer ${ }^{18} \mathrm{~F}$-galacto-RGD in cancer patients. J. Nucl. Med. 46:1333-1341.

70. Sutcliffe-Goulden, J.L., M.J. O'Doherty, P.K. Marsden, I.R. Hart, J.F. Marshall, and S.S. Bansal. 2002. Rapid solid phase synthesis and biodistribution of ${ }^{18} \mathrm{~F}$ labelled linear peptides. Eur. J. Nucl. Med. Mol. Imaging 29:754-759.

71. Ogawa, M., K. Hatano, S. Oishi, Y. Kawasumi, N. Fujii, M. Kawaguchi, R. Doi, M. Imamura, et al. 2003. Direct electrophilic radiofluorination of a cyclic RGD peptide for in vivo $\alpha_{v} \beta_{3}$ integrin related tumor imaging. Nucl. Med. Biol. 30:1-9.

72. Chen, X., R. Park, A.H. Shahinian, M. Tohme, V. Khankaldyyan, M.H. Bozorgzadeh, J.R. Bading, R.A. Moats, et al. 2004. ${ }^{18}$ F-labeled RGD peptide: initial evaluation for imaging brain tumor angiogenesis. Nucl. Med. Biol. 31:179-189.

73. Chen, X., R. Park, A.H. Shahinian, J.R. Bading, and P.S. Conti. 2004. Pharmacokinetics and tumor retention of 125 -labeled RGD peptide are improved by PEGylation. Nucl. Med. Biol. 31:11-19.

74. Gottschalk, K.E. and H. Kessler. 2002. The structures of integrins and integrinligand complexes: implications for drug design and signal transduction. Angew. Chem. Int. Ed. Engl. 41:3767-3774.

75. Chen, X., E. Sievers, Y. Hou, R. Park, M. Tohme, R. Bart, R. Bremner, J.R. Bading, and P.S. Conti. 2005. Integrin $\alpha_{\vee} \beta_{3}$-targeted imaging of lung cancer. Neoplasia 7:271-279.

76. Chen, X., C. Plasencia, Y. Hou, and N. Neamati. 2005. Synthesis and biological evaluation of dimeric RGD peptide-paclitaxel conjugate as a model for integrintargeted drug delivery. J. Med. Chem. 48:1098-1106.

77. Mammen, M., S. Chio, and G.M. Whitesides. 1998. Polyvalent interactions in biological systems: implications for design and use of multivalent ligands and inhibitors. Angew. Chem. Int. Ed. Engl. 37:2755-2794.

78. Zhang, X., Z. Xiong, X. Wu, W. Cai, J.R. Tseng, S.S. Gambhir, and X. Chen. Quantitative PET imaging of tumor integrin $\alpha_{v} \beta_{3}$ expression with [18F]FRGD2. J. Nucl. Med. (In press).

79. Logan, J. 2000. Graphical analysis of PET data applied to reversible and irreversible tracers. Nucl. Med. Biol. 27:661-670

80. Kawatsu, S., T. Kato, A. Nagano-Saito, K. Hatano, K. Ito, and T. Ishigaki. 2003. New insight into the analysis of 6-[18F]fluoro-L-DOPA PET dynamic data in brain tissue without an irreversible compartment: comparative study of the Patlak and Logan analyses. Radiat. Med. 21:47-54.

81. Thibault, G. 2000. Sodium dodecyl sulfate-stable complexes of echistatin and RGD-dependent integrins: a novel approach to study integrins. Mol. Pharmacol. 58:1137-1145.

82. Anderson, C.J., L.A. Jones, L.A. Bass, E.L. Sherman, D.W. McCarthy, P.D. Cutler, M.V. Lanahan, M.E. Cristel, et al. 1998. Radiotherapy, toxicity and dosimetry of copper-64-TETA-octreotide in tumor-bearing rats. J. Nucl. Med. 39:1944-1951.

83. Pauwels, S., R. Barone, S. Walrand, F. Borson-Chazot, R. Valkema, L.K. Kvols, E.P. Krenning, and F. Jamar. 2005. Practical dosimetry of peptide receptor radionuclide therapy with ${ }^{90}$ Y-labeled somatostatin analogs. J. Nucl. Med. 46(Suppl 1):92S-98S.

84. Chen, X., Y. Hou, M. Tohme, R. Park, V. Khankaldyyan, I. Gonzales-Gomez, J.R. Bading, W.E. Laug, and P.S. Conti. 2004. Pegylated Arg-Gly-Asp peptide: ${ }^{64} \mathrm{Cu}$ labeling and PET imaging of brain tumor $\alpha_{4} \beta_{3}$-integrin expression. J. Nucl. Med. 45:1776-1783

85. Posey, J.A., M.B. Khazaeli, A. DelGrosso, M.N. Saleh, C.Y. Lin, W. Huse, and A.F. LoBuglio. 2001. A pilot trial of Vitaxin, a humanized anti-vitronectin receptor (anti $\alpha_{1} \beta_{3}$ ) antibody in patients with metastatic cancer. Cancer Biother. Radiopharm. 16:125-132.

86. Patel, S.R., J. Jenkins, N. Papadopolous, M.A. Burgess, C. Plager, J. Gutterman, and R.S. Benjamin. 2001. Pilot study of vitaxin-an angiogenesis inhibitor-in patients with advanced leiomyosarcomas. Cancer 92:1347-1348.

87. Gambhir, S.S., J. Czernin, J. Schwimmer, D.H. Silverman, R.E. Coleman, and M.E. Phelps. 2001. A tabulated summary of the FDG PET literature. J. Nucl. Med. 42:1S-93S.

Address correspondence to:

Xiaoyuan Chen

Molecular Imaging Program at Stanford (MIPS)

Department of Radiology and Bio-X Program

Stanford University School of Medicine

1201 Welch Road, Rm. P095

Stanford, CA 94305-5484, USA

e-mail: shawchen@stanford.edu 